\title{
Deactivation and Regeneration of Sulfonated Carbon Catalysts in Hydrothermal Reaction Environments
}

\author{
David Scholz, ${ }^{[a, b]}$ Oliver Kröcher ${ }^{[a, b]}$ and Frédéric Voge ${ }^{\star[a, c]}$
}

\begin{abstract}
The deactivation pathways of sulfonated carbon catalysts prepared from different carbons were studied during the aqueousphase hydrolysis of cellobiose under continuous flow conditions. Sulfonation of carbon materials with a low degree of graphitization, introduced sulfonic acid groups that are partially stable even during prolonged exposure to harsh hydrothermal treatments $\left(180{ }^{\circ} \mathrm{C}\right)$. Physicochemical characterization of hydrothermally treated materials coupled with treatment of model compounds for sulfonic acids demonstrated that stability is related to the presence of activating and deactivating substituents on the aromatic system. Besides sulfonic acid group leaching, a hitherto unknown mode of deactivation was identified that proceeds via ion exchange of cations contained in the aqueous feed and protons of sulfonic acid groups. Proton leaching is a fully reversible mode of deactivation via treatment of the spent catalysts with strong Brønsted acids. Through a combined approach of physicochemical characterization, catalytic testing and hydrothermal treatment a methodology for preparation of catalytically stable sulfonic acid group bearing carbon materials is established.
\end{abstract}

\section{Introduction}

Diminishing fossil fuel resources have reinforced the need to develop strategies for the production of fuels and chemicals from renewable resources. Due to its widespread abundance lignocellulosic biomass has been discussed intensely as an alternative chemical feedstock ${ }^{[1]}$ to replace petroleum-based production of fuels and chemicals. However, in contrast to petroleum-based feedstocks, the $\mathrm{C}_{5}$ and $\mathrm{C}_{6}$ carbohydrates of biomass (in other words, the hemi-cellulose and cellulose constituents of biomass) cannot be reacted in the gas phase due to their very low vapor pressure and tendency to undergo thermally-induced decomposition reactions. Consequently, chemical valorization strategies in the liquid phase providing access to the carbon bound in the form of polymeric substances have to be developed, to enable downstream upgrading to value added fuels and chemicals. Depolymerization of the cellulosic constituents of lignocellulose can be achieved via hydrolysis of the glycosidic bond between $\mathrm{C}_{6}$ and $\mathrm{C}_{5}$ carbohydrates. ${ }^{[2]}$ Different approaches including enzymatic, ${ }^{[3]}$ thermochemical ${ }^{[4]}$

[a] D. Scholz, Prof. O. Kröcher, Prof. F. Vogel

Bioenergy and Catalysis Laboratory

Paul Scherrer Institut, 5232 Villigen PSI, Switzerland

E-mail: frederic.vogel@psi.ch

[b] D. Scholz and Prof. O. Kröcher

Institute of Chemical Sciences and Engineering

Ecole polytechnique fédérale de Lausanne

EPFL SB ISIC-GE, 1015 Lausanne, Switzerland

[c] Prof. F. Vogel

Institute of Bioenergy and Resource Efficiency

University of Applied Sciences and Arts Northwestern Switzerland 5210 Windisch, Switzerland and Brønsted acid ${ }^{[5]}$-catalyzed hydrolysis processes have been investigated. Enzyme-based processes generally suffer from slow reaction rates and limited catalyst stability, thereby rendering enzymatic hydrolysis processes economically unfeasible. ${ }^{[3]}$ Hydrolysis of cellulosic biomass can also be achieved in sub- or super-critical water. ${ }^{[4]}$ In this case, hydrolysis is catalyzed by protons derived from the self-ionization equilibrium of water, which is shifted to higher values with increasing temperature ${ }^{[6]}$ However, the large heating rates and low residence times required to achieve selective formation of carbohydrates are a challenging technical obstacle and stand in a direct trade-off with the high substrate loadings required for an economically viable production. Homogeneous acid-based processes employing $\mathrm{H}_{2} \mathrm{SO}_{4}{ }^{[7]}$, $\mathrm{HCl}^{[8]}$, or $\mathrm{HF}^{[9]}$ as acid catalysts have been demonstrated to proceed in good to excellent yields (even in technical scale applications using real lignocellulose as a feedstock). However, larger-scale implementations have not been realized due to the high technical and economic barriers associated with catalyst recovery ${ }^{[8]}$ or neutralization. ${ }^{[7 c]}$ Hence, solid acid catalysts have been studied as alternatives to conventional homogeneous acid catalysts. ${ }^{[10]}$ Heterogeneous catalysts can be effectively recovered from the product mixture and are typically less corrosive towards reactor- and pipingmaterials. ${ }^{[11]}$ Although some very interesting results using solid Brønsted acid catalysts such as zeolites, ${ }^{[12]}$ polymer-based materials, ${ }^{[13]}$ metal oxides ${ }^{[12,14]}$ or functionalized silica catalyst ${ }^{[15]}$ have been reported in recent years, all materials have in common the lack of pronounced stability under hydrotherma reaction conditions. ${ }^{[16]}$ The development of a stable heterogeneous Brønsted-acid catalyst would consequently be a milestone in designing sustainable production processes of fuels and chemicals from lignocellulose. Furthermore, such materials could replace homogeneous acid catalysts used in plenty of other liquid phase processes.

Carbon based materials are regarded as a promising alternative to conventional solid acid catalysts, owing to the high stability of the carbon framework under hydrothermal reaction conditions. ${ }^{[17]}$ The introduction of acidic carboxylic- or sulfonic-acid-based surface sites can be accomplished via different chemical oxidation $^{[18]}$ and sulfonation ${ }^{[19]}$ strategies. The approach of sulfonation has been demonstrated for a large number of different carbon based materials including polyaromatic molecules, ${ }^{[20]}$ activated carbons, ${ }^{[21]}$ mesoporous carbons, ${ }^{[22]}$ hydrothermal carbon, ${ }^{[19]}$ carbon-silica composites, ${ }^{[23]}$ carbon nanotubes, ${ }^{[24]}$ graphene-like nanoporous carbon, ${ }^{[25]}$ and carbons derived from the incomplete carbonization of carbohydrate precursors. ${ }^{[26]}$ Despite the higher stability of the carbon framework, sulfonic acid groups are prone to leaching in hydrothermal reaction environments due to the tendency of the C-S bond to undergo acid-catalyzed hydrolysis (desulfonation). ${ }^{[27]}$ The latter effect is strongly related to the solvent as well as to the severity (temperature) of the treatment. Sulfonated carbons derived from incompletely carbonized carbohydrates have proven to be stable during batch-based 
recyclability tests in alcohols over a wide range of temperatures $\left(80-180{ }^{\circ} \mathrm{C}\right) .{ }^{[26 a]}$ In a similar approach, Fraile et al. found that 75 to $99 \%$ of the sulphur in different sulfonated carbon catalysts was retained after refluxing in methanol. ${ }^{[28]}$ Interestingly, however, it was found that the catalysts deactivated in methanol due to an irreversible formation of sulfonate esters. Comparable sulphur stability was also observed for a sulfonated carbon prepared from incompletely carbonized cellulose, during 25 reuse experiments in water at $100{ }^{\circ} \mathrm{C} .^{[26 c]}$ Leaching of sulfonic acid groups can, however, be induced by exposure to aqueous environments at significantly more severe conditions. Onda et al. ${ }^{[21 c]}$ showed, for instance, that $24 \%$ of the initially present sulfonic acid groups in a sulfonated activated carbon-based catalyst leached when subjected to liquid water at $200{ }^{\circ} \mathrm{C}$. Further, studies revealed that the hydrothermal stability of sulfonic acid groups in a sulfonated activated carbon was dependent on the severity of the hydrothermal treatment. ${ }^{[21 a]}$ The sulfonic acid group density (of initially $0.58 \mathrm{mmol} \mathrm{g}^{-1}$ ) decreased to $0.35,0.30$, and $0.20 \mathrm{mmol} \mathrm{g}^{-1}$ after treatment at 150,200 and $225^{\circ} \mathrm{C}$ in hot compressed water. These results indicate that the sulfonation of carbon materials entails the formation of a distribution of sulfonic acid sites with varying hydrothermal stability; this suggests in turn that the stability of sulfonic acid groups is associated with the local carbon structure and chemical environment of the sulfonic acid groups. Further substantiation to this analysis was provided by Hara et al. ${ }^{[20]}$ by comparing the activity and stability of differently prepared sulfonated carbon catalysts. Materials prepared by sulfonationcarbonization of naphthalene were found to be stable, whereas materials derived from the sulfonation of incompletely carbonized resins, amorphous glassy carbon, activated carbon or natural graphite formed materials with very low acid site density $\left(0.05-0.15 \mathrm{mmol} \mathrm{g}^{-1}\right)$ that had no activity for esterification reactions and leached all sulfonic acid groups when exposed to water at $50^{\circ} \mathrm{C}$. In an effort to unravel the relation between structure and stability, Anderson et al. ${ }^{[19]}$ employed solid-state ${ }^{13} \mathrm{C}-\mathrm{NMR}$ to characterize the structure of materials prepared by direct sulfonation or diazotization-sulfonation of incompletely carbonized carbohydrates and hydrothermal carbon, as well as by dehydration-sulfonation of glucose. Although the materials were shown to possess fundamentally different structures, all materials leached $50-90 \%$ of the sulphur after repeated hydrothermal treatment at $160{ }^{\circ} \mathrm{C}$ and did not have activity in esterification reactions any longer. Consequently, a clear guideline for synthesizing hydrothermally stable sulfonated carbon catalysts could not be established.

Apart from sulfonic acid group leaching, deactivation of sulfonated carbon catalysts may occur via proton leaching induced by ion exchange processes with cationic mineral species. ${ }^{[21 \mathrm{~b}]}$ This pathway would be particularly relevant during biomass conversion processes, due to the natural mineral content of lignocellulose. ${ }^{[2]}$ It has been argued that materials featuring only weak Brønsted acid sites display a reduced tendency to undergo ion exchange processes, and would consequently be more stable during hydrolysis reactions in presence of solubilized mineral species. ${ }^{[29]}$ However, this argumentation has so far not been based on experimental results demonstrating the influence of ion exchange processes on the stability of sulfonated carbon catalysts.

The issues addressed before unequivocally show the necessity to resolve the discrepancies reported in literature and to give a comprehensive picture of hydrothermal stability of sulfonic acid groups in carbon based materials. In this contribution, we therefore explore the impact of hydrothermal reaction environments on the structure and stability of sulfonated carbon catalysts. By combining this analysis with a systematic study of the stability of sulfonic acid groups in well-defined model systems representative of the chemical environment found in sulfonated carbon catalysts we provide insights into the factors defining the stability of sulfonic acid groups in carbon matrices. On the basis of these results we propose a protocol for the synthesis of sulfonated carbon catalysts featuring hydrothermally stable sulfonic acid groups. Furthermore we elucidate the influence of different deactivation pathways on the catalytic performance of sulfonated carbon catalysts through long term continuous flow stability tests in the liquid phase. In particular we shed light on the detrimental effect of ion exchange processes on catalysts stability and present strategies that can be used to restore activity or improve stability.

\section{Results and Discussion}

Influence of hydrothermal treatment on the structure of sulfonated carbons: To investigate the influence of a hydrothermal reaction environment on the stability of sulfonated carbons, several incompletely carbonized materials prepared by cellulose carbonization at temperatures between $350{ }^{\circ} \mathrm{C}$ and $750{ }^{\circ} \mathrm{C}$, were sulfonated (denoted, carbonization temperature$\mathrm{SO}_{3} \mathrm{H}$ ) and subsequently treated in hot compressed water at $180{ }^{\circ} \mathrm{C}$ (denoted, carbonization temperature- $\mathrm{SO}_{3} \mathrm{H}-\mathrm{HT}$ ). Additionally, reference materials were synthesized by sulfonation of a commercially available activated carbon (CA1) and a high-surface area graphite (HSAG). Particle morphology and textural properties of sulfonated and hydrothermally treated materials were studied with SEM and gas-physisorption, respectively. The SEM images (Figure S1) of samples derived from incompletely carbonized cellulose show particles with a rough surface morphology that lacked any ordered structural features. The particle size of the different samples was highly irregular (up to approx. $150 \mu \mathrm{m}$ ), without any pronounced trend with carbonization temperature. These characteristics are consistent with previous studies. ${ }^{[19]}\left[{ }^{[26 b]}\right.$ All samples derived from incompletely carbonized cellulose featured very low BET areas in the range of 2.0-2.4 $\mathrm{m}^{2} \mathrm{~g}^{-1}$ (Table 1), suggesting that the samples possessed no accessible micro- or mesoporosity. This is further supported by the fact that the krypton adsorption isotherms of the samples (Figure S2) resembled type II (nonporous or macroporous solids). The specific surface areas for the samples prepared from incompletely carbonized carbons slightly increased during hydrothermal treatment, in particular for samples prepared at carbonization temperatures $>450{ }^{\circ} \mathrm{C}$. This is tentatively attributed to the formation of smaller and less 
elongated particles for the samples $450-\mathrm{SO}_{3} \mathrm{H}, 550-\mathrm{SO}_{3} \mathrm{H}$ and $750-\mathrm{SO}_{3} \mathrm{H}$. The surface area and total pore volume of sulfonated CA1 and HSAG was unaffected by the hydrothermal treatment. The samples derived from CA1 and HSAG displayed type IVa (mesoporous) and II nitrogen adsorption isotherms after sulfonation and hydrothermal treatment, respectively.

Table 1. Properties of sulfonated and hydrothermally treated carbon samples.

\begin{tabular}{|c|c|c|c|c|}
\hline Catalyst & $C^{[a]}$ & $\begin{array}{l}-\mathrm{SO}_{3} \mathrm{H} \\
\left(\mu \mathrm{mol} \mathrm{g}{ }^{-1}\right)^{[b]}\end{array}$ & $\begin{array}{l}\text { BET } \\
\text { Area } \\
\left(\mathrm{m}^{2} \mathrm{~g}^{-1}\right)^{[\mathrm{c}] /[\mathrm{d}]}\end{array}$ & $\begin{array}{l}\text { Acidic } \\
\text { groups } \\
\left.(\mu \mathrm{mol} \mathrm{g})^{-1}\right)^{[e]}\end{array}$ \\
\hline $350-\mathrm{SO}_{3} \mathrm{H}$ & 54.0 & 2028 & $2.1^{[c]}$ & 3727 \\
\hline $350-\mathrm{SO}_{3} \mathrm{H}-\mathrm{HT}$ & 62.8 & 850 & $2.2^{[\mathrm{c}]}$ & 3874 \\
\hline $400-\mathrm{SO}_{3} \mathrm{H}$ & 58.7 & 1606 & $2.0^{[c]}$ & 3497 \\
\hline $400-\mathrm{SO}_{3} \mathrm{H}-\mathrm{HT}$ & 64.3 & 631 & $2.4^{[\mathrm{c}]}$ & 2962 \\
\hline $450-\mathrm{SO}_{3} \mathrm{H}$ & 75.5 & 678 & $2.4^{[\mathrm{c}]}$ & 747 \\
\hline $450-\mathrm{SO}_{3} \mathrm{H}-\mathrm{HT}$ & 80.1 & 210 & $3.9^{[c]}$ & 310 \\
\hline $550-\mathrm{SO}_{3} \mathrm{H}$ & 77.2 & 1131 & $2.3^{[\mathrm{c}]}$ & 1264 \\
\hline $550-\mathrm{SO}_{3} \mathrm{H}-\mathrm{HT}$ & 86.5 & 319 & $2.9^{[c]}$ & 27 \\
\hline $750-\mathrm{SO}_{3} \mathrm{H}$ & 74.7 & 1946 & $2.1^{[\mathrm{c}]}$ & 1324 \\
\hline $750-\mathrm{SO}_{3} \mathrm{H}-\mathrm{HT}$ & 85.1 & 372 & $3.4^{[c]}$ & 242 \\
\hline $\mathrm{CA} 1-\mathrm{SO}_{3} \mathrm{H}$ & 65.3 & 1328 & $859^{[\mathrm{d}]}$ & 2806 \\
\hline $\mathrm{CA} 1-\mathrm{SO}_{3} \mathrm{H}-\mathrm{HT}$ & 70.4 & 718 & $878^{[\mathrm{d}]}$ & 2696 \\
\hline $\mathrm{HSAG}-\mathrm{SO}_{3} \mathrm{H}$ & 90.9 & 134 & $476^{[\mathrm{d}]}$ & 10 \\
\hline $\mathrm{HSAG}-\mathrm{SO}_{3} \mathrm{H}-\mathrm{HT}$ & 92.0 & 72 & $466^{[\mathrm{d}]}$ & 0 \\
\hline
\end{tabular}

[a] Determined by elemental analysis. [b] Calculated from sulphur content. [c] Determined by Kr-physisorption. [d] Determined by $\mathrm{N}_{2}$ physisorption. [e] Determined by Boehm titration.

The changes in the elemental composition of the samples prepared from incompletely carbonized cellulose indicate the reconstruction of materials at higher carbonization temperatures (Figure S3.A), during sulfonation (Figure S3.B) and upon hydrothermal treatment (Figure S3.C). When the carbonization temperature was ramped from $350{ }^{\circ} \mathrm{C}$ to $750{ }^{\circ} \mathrm{C}$, the carbon content increased. Simultaneously, the oxygen content declined due to the thermal instability of oxygen containing functional groups (thermal instability values: carboxylic-acids $200-400{ }^{\circ} \mathrm{C}$, lactones $350-627{ }^{\circ} \mathrm{C}$, phenols $600-700{ }^{\circ} \mathrm{C}$, ethers $700{ }^{\circ} \mathrm{C}$, carbonyl groups $\left.700-980{ }^{\circ} \mathrm{C}\right)^{[30]}$. The treatment with fuming sulphuric acid (20 wt\% $\mathrm{SO}_{3}$ in $\mathrm{H}_{2} \mathrm{SO}_{4}$ ) introduced sulphur into the materials. As discussed later in detail, sulphur introduced during sulfonation is partially removed upon hydrothermal treatment of sulfonated materials.

In order to gain deeper insight into the structural changes occurring during the various treatments and the chemistry related to that, Fourier transform-infrared (FTIR) spectra were recorded (Figure 1). The FTIR spectra of the samples $350-\mathrm{SO}_{3} \mathrm{H}$, $400-\mathrm{SO}_{3} \mathrm{H}$ and $\mathrm{CA} 1-\mathrm{SO}_{3} \mathrm{H}$ clearly show the formation of two absorption bands centered at $1040 \mathrm{~cm}^{-1}$ and $1168 \mathrm{~cm}^{-1}$. The bands are assigned to the symmetric $\mathrm{v}_{\mathrm{s}}(\mathrm{O}=\mathrm{S}=\mathrm{O})$ and asymmetric $\mathrm{v}_{\mathrm{as}}(\mathrm{O}=\mathrm{S}=\mathrm{O})$ stretching modes in $\mathrm{SO}_{3},{ }^{[31]}$ and thus confirm the presence of sulfonic acid groups. Interestingly, the intensities of the bands for the samples $450-\mathrm{SO}_{3} \mathrm{H}$ and 550 $\mathrm{SO}_{3} \mathrm{H}$ were quite low, while the bands were not detected for the samples $750-\mathrm{SO}_{3} \mathrm{H}$ or $\mathrm{HSAG}-\mathrm{SO}_{3} \mathrm{H}$, despite high sulphur loadings. This observation is attributed to the strong IR absorptivity of carbon frameworks with a high degree of graphitization. The higher degree of graphitization in these samples can be inferred from the decreasing intensity of the absorption band at $1593 \mathrm{~cm}^{-1}$, which is characteristic of aromatic structures $\left(\mathrm{v}(\mathrm{C}=\mathrm{C})^{[30]}\right)$. This implies that the graphitic degree of the materials correlated with the carbonization temperature, i.e. materials carbonized at higher temperature are composed of larger and more extended polyaromatic layers where the $\mathrm{v}(\mathrm{C}=\mathrm{C})$ vibration is not IR active. The presence of oxygen containing surface functionalities is evident from the broad and unresolved

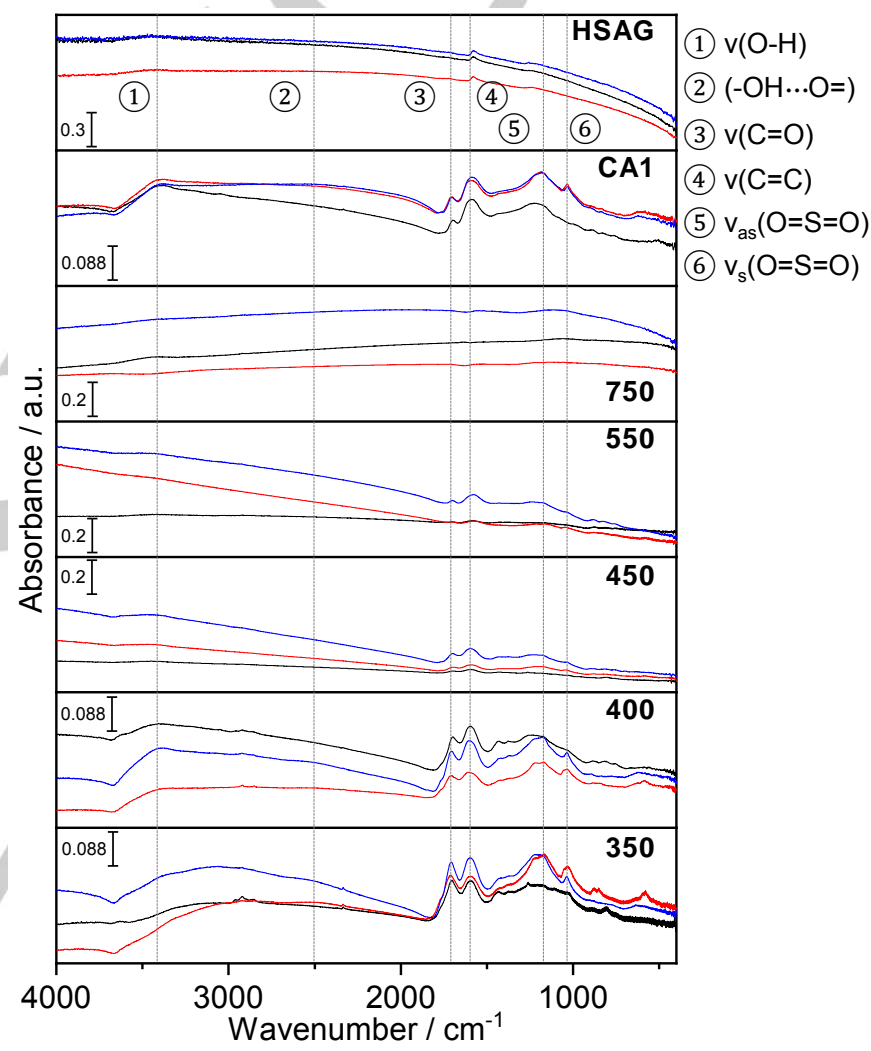

Figure 1. FTIR spectra of carbonized (-), sulfonated (-) and hydrothermally treated samples (-).

signal in the region $1150-1400 \mathrm{~cm}^{-1}$ for sulfonated and hydrothermally treated samples. According to literature, ${ }^{[30]}$ the absorption in this region stems from $\mathrm{v}(\mathrm{C}-\mathrm{O})$ stretching vibrations in ethers $\left(1000-1300 \mathrm{~cm}^{-1}\right)$, phenols $\left(1000-1200 \mathrm{~cm}^{-1}\right)$, carboxylic acids (1120-1200 $\left.\mathrm{cm}^{-1}\right)$ and lactones (1160-1370 $\left.\mathrm{cm}^{-1}\right)$. On the other hand, the absorption band at $1707 \mathrm{~cm}^{-1}$ is characteristic of carbonyl-containing surface groups $(\mathrm{v}(\mathrm{C}=\mathrm{O})$ stretching vibration). ${ }^{[30]}$ The decrease in intensity of the absorption bands associated with $\mathrm{C}-\mathrm{O}$ and $\mathrm{C}=\mathrm{O}$ containing surface groups for samples prepared at higher carbonization 
temperatures is in line with the observed trend in elemental composition and suggests that these samples possess a lower density of oxygen-containing surface functionalities. Absorption in the wavenumber region of $3200-3500 \mathrm{~cm}^{-1}$ is assigned to the $\mathrm{v}(\mathrm{O}-\mathrm{H})$ stretching vibration. ${ }^{[30]}$ The spectra of the samples prepared at $350{ }^{\circ} \mathrm{C}$ and $400{ }^{\circ} \mathrm{C}$ additionally show a broad feature centered at $2500 \mathrm{~cm}^{-1}$ after sulfonation and hydrothermal treatment. This is linked to an overtone of the $(-\mathrm{OH} \cdots \mathrm{O}=)$ bending mode of Brønsted acids that participate in hydrogen bonding. ${ }^{[2]}$ Treatment of the samples in hot compressed water $\left(180^{\circ} \mathrm{C}\right.$, $16.5 \mathrm{~h}$ ) induced changes in the surface chemistry of materials. Firstly, the reversibility of the sulfonation reaction under hydrothermal conditions ${ }^{[27]}$ causes leaching of sulfonic acid groups as evidenced by the reduction of the sulphur content (Figure S3.B and S3.C). As discussed later in more detail, the FTIR spectra of the samples $350-\mathrm{SO}_{3} \mathrm{H}, 400-\mathrm{SO}_{3} \mathrm{H}$ and $\mathrm{CA} 1-$ $\mathrm{SO}_{3} \mathrm{H}$ interestingly still contain clearly identifiable vibrations associated with the presence of sulfonic acid groups. Secondly, absorption in the $\mathrm{v}(\mathrm{C}-\mathrm{O})$ and $\mathrm{v}(\mathrm{C}=\mathrm{O})$ region increased, indicating that the exposure of sulfonated carbon materials to these conditions induced the formation of additional oxygen-containing surface groups. This is also confirmed by comparing the total amount of surface functionalities present in the samples 350 $\mathrm{SO}_{3} \mathrm{H}, 400-\mathrm{SO}_{3} \mathrm{H}$ and $\mathrm{CA} 1-\mathrm{SO}_{3} \mathrm{H}$ before and after hydrothermal treatment. Although the sulphur content and thereby the sulfonic acid group density (assuming all sulphur is present in the form of sulfonic acid groups) is drastically reduced, the total amount of acidic surface groups (sulfonic + carboxylic + phenolic) in these materials decreases only slightly or even increases (Table 1). To investigate changes in the carbon structure occurring at higher carbonization temperatures and during hydrothermal treatment, the samples derived from incomplete cellulose carbonization as well as the reference materials were analyzed with X-ray diffraction and Raman spectroscopy. The X-ray diffraction patterns of the samples after carbonization, sulfonation and hydrothermal treatment are shown in Figure 2. Samples prepared by incomplete carbonization and the activated carbon CA1 are characterized by two broad signals of low intensity at $2 \theta \approx 24^{\circ}$ and $2 \theta \approx 43^{\circ}$ originating from the $(002)$ and $(101)$ or $(100)$ reflections in graphitic materials. ${ }^{[3]}$ The diffraction patters are typical of turbostratic carbons featuring highly amorphous carbon structures characterized by haphazardly orientated polyaromatic domains. Upon increasing the carbonization temperature, the resolution and intensity of the (002) diffraction increases due to the tendency of the carbon framework to gradually graphitize (lateral growth and stacking of polyaromatic domains ${ }^{[33]}$ ). Comparing the diffraction patterns of sulfonated and hydrothermally treated materials shows no significant change of the reflections. Hence, the structural elements of the carbon framework associated with the (002) and (101) or (100) reflection are unaffected by treatment in hot compressed water at $180^{\circ} \mathrm{C}$. A more profound insight into the carbon structure of the different samples and the impact of hydrothermal conditions on these was established by means of Raman spectroscopy. Figure 3 shows the baseline corrected and normalized Raman spectra of samples after sulfonation and hydrothermal treatment. The first-order Raman spectra of poorly organized carbon materials are characterized by two strongly overlapping peaks termed the D-defect $\left(\approx 1000-1500 \mathrm{~cm}^{-1}\right)$ and G-graphite $\left(\approx 1500-1700 \mathrm{~cm}^{-1}\right)$ band, associated with disordered and ordered graphene layers, respectively. ${ }^{[34]}$ The $D$ and $G$ band

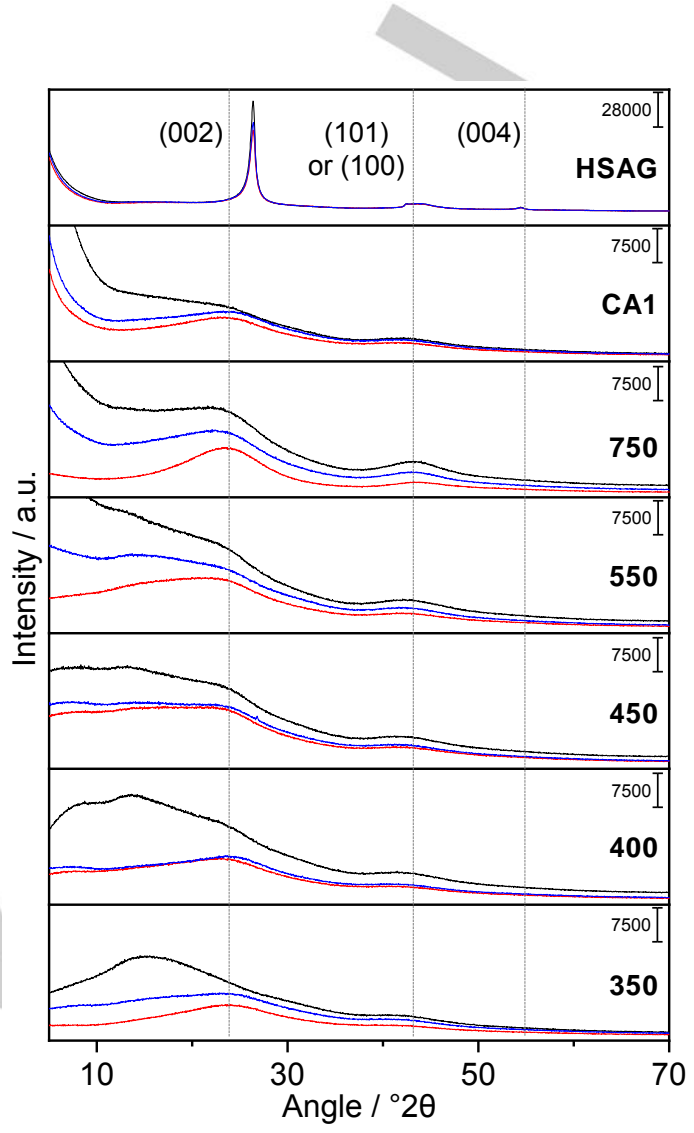

Figure 2. X-ray diffraction patterns of carbonized (-), sulfonated (-) and hydrothermally treated samples (-).

form as a consequence of overlapping vibrational modes of carbon atoms in polyene structures (D4), at the edge of graphene layers (D1), outside of aromatic layers such as amorphous or molecular carbon (i.e. functional groups) structures (D3), and lattice vibrations in graphitic carbon (G) as well as surface graphene layers (D2). ${ }^{[34]}$ The Raman spectrum of HSAG is primarily composed of the comparatively sharp D1 and $G$ bands (Figure S4). The latter exhibits a shoulder attributed to the D2 band. Thus, the carbon framework of HSAG compromises carbon atoms in both an ideal and in a partially disturbed graphitic lattice. In contrast, the Raman spectra of materials derived from incomplete carbonization, as well as CA1, are composed of two very broad and strongly overlapping peaks with contributions from the D4, D1, D3, G and D2 bands (Figure S4). The spectra are typical of carbonaceous materials with a highly heterogeneous carbon structure, as found, for example, for soot. ${ }^{[34-35]}$ Accordingly, the structure encompasses contributions from graphitic lattice structures, highly defective graphitic lattices and, to a large extent, amorphous-molecular 
carbon structures outside of polyaromatic layers. The relative contribution of these structural elements to the Raman spectra changes with carbonization temperature. As the carbonization

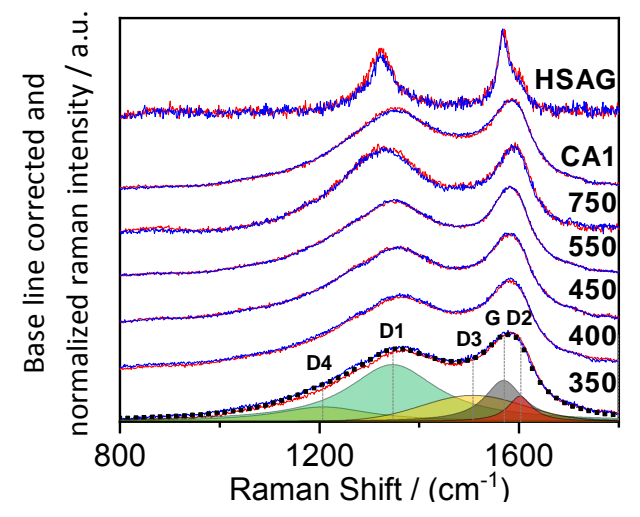

Figure 3. Raman spectra of sulfonated (-), hydrothermally treated materials (-) and fitted D4 band $(\square)$, D1 band $(\square)$, D3 band $(\square)$, G band ( $\square$ ), D2 band ( $\square$ ) and sum of bands $(\mathbf{a})$ for the sample $350-\mathrm{SO}_{3} \mathrm{H}$.

temperature increases the relative contribution of carbon atoms in crystalline graphite-like domains to the overall Raman spectra increases. This analysis is supported by considering the area ratio $R 2(D 1 /(D 1+G+D 2))$ (Figure 4) derived from the deconvolution of the Raman spectra by using a combination of four Lorentzian peaks (D4, D1, G and D2) and one Gaussian peak (D3) ${ }^{[34]}$ The $\mathrm{R} 2$ ratio is typically $>0.5$ in poorly organized and $<0.5$ in well-organized materials and has thus been suggested to be a measure of the degree of graphitization. ${ }^{[35 a]}$ The $\mathrm{R} 2$ ratio for samples derived from incomplete carbonization increases at higher carbonization temperatures from 0.70 to 0.76 , due to the rising contribution of carbon atoms in polyaromatic domains (D1) organized in a disturbed graphitic lattice. This analysis is consistent with the observation that the intensity of the (002) reflection (Figure 2) associated with stacking of polyaromatic layers, is greater for samples prepared at higher carbonization temperatures. The formation of larger polyaromatic domains is expected to occur via the gradual transformation of amorphous-molecular carbon (D3) at increasing carbonization temperatures. The large contribution of amorphous-molecular carbon to the Raman spectra of materials carbonized at low temperatures is consistent with the results of the ${ }^{13} \mathrm{C}$ solid state NMR structure analysis by Anderson et al. ${ }^{[19]}$ The authors stated that sulfonated samples carbonized a low temperature $\left(350{ }^{\circ} \mathrm{C}\right)$ were composed of linked furan, benzene, benzofuran, naphthalene and anthracene rings, whereas a sample prepared at higher temperature $\left(450{ }^{\circ} \mathrm{C}\right)$ consisted of larger polyaromatic structures. The formation of highly organized carbon structures, as, for example, in highly oriented pyrolytic graphite's, resulting in lower values for the R2 ratio, ${ }^{[34]}$ would require significantly higher temperatures at ambient pressures. The tendency of materials to form carbon structures with reduced structural heterogeneity at higher carbonization temperatures, i.e. with higher degrees of graphitization, is likewise evidenced in the full width at half maximum (FWHM) of the fitted D1 and $G$ bands (Figure S5). As the carbonization temperature is increased from $350{ }^{\circ} \mathrm{C}$ to $750{ }^{\circ} \mathrm{C}$, the $\mathrm{FWHM}$ of D1 and $\mathrm{G}$ bands decreases from 226 to $167 \mathrm{~cm}^{-1}$ and 98 to

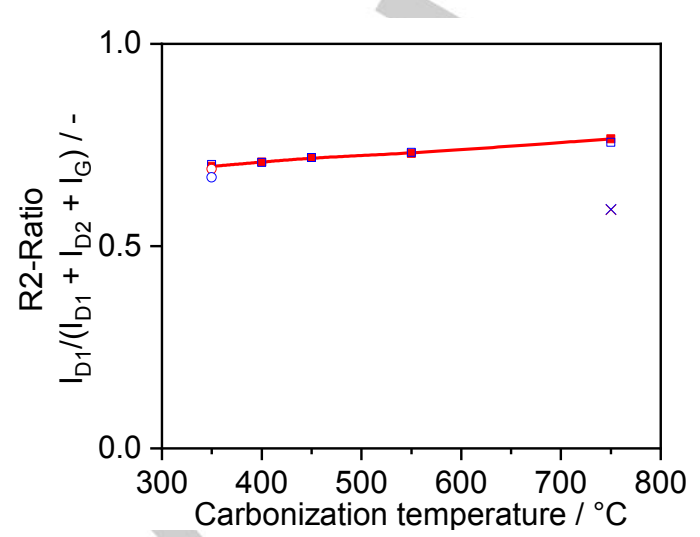

Figure 4. R2 ratio of sulfonated (") and hydrothermally treated ( $\square$ ) samples derived from incomplete cellulose carbonization, Norit CA1 (०/०) and HSAG $(x / x) . C A 1$ and $H S A G$ have been plotted at $350{ }^{\circ} \mathrm{C}$ and $750{ }^{\circ} \mathrm{C}$, respectively, for the purpose of comparison.

$56 \mathrm{~cm}^{-1}$, respectively. The strong overlap of the spectra with those of sulfonated materials (Figure 3) suggests that hydrothermal treatment had no pronounced influence on the carbon structure. Consequently, R2 values determined from the deconvolution of the Raman spectra of the hydrothermally treated samples (Figure 4) were only slightly different from those determined for the sulfonated samples. This implies that treatment of carbonaceous materials in hot compressed water at $180{ }^{\circ} \mathrm{C}$ does not induce profound changes to the carbon structure. This statement can be supported by XRD measurements (Figure 2). No pronounced changes in the crystalline structure could be observed during hydrothermal treatment.

Catalytic activity/stability of sulfonated carbons: To assess the catalytic performance of the different sulfonated carbons, Brønsted acid catalyzed hydrolysis of cellobiose was chosen as probe reaction. The catalysts were tested for their catalytic activity and stability under continuous flow conditions during 24 hours' time on stream (TOS). In the presence of species with Brønsted acidity, cellobiose undergoes a sequence of reactions (Scheme 1) that is initialized with the hydrolysis of the $\beta-1,4-$ glycosidic bond, forming two equivalents of $\mathrm{C}_{6}$ carbohydrates. $\mathrm{C}_{6}$ carbohydrates can sequentially undergo intra- and intermolecular dehydration to levoglucosan and 5-(hydroxymethyl) furfural (5-HMF). At sufficiently long reaction times, 5-HMF can be rehydrated to levulinic and formic acid. Figure 5 shows the catalyst productivity of the different sulfonated carbon catalysts over $24 \mathrm{~h}$ TOS. Residence time and catalyst mass were chosen to achieve conversion levels below $100 \%$ (Figure S6). Reactions were performed at a temperature of $130{ }^{\circ} \mathrm{C}$ to avoid autohydrolysis of the substrate as side-reaction. The materials tested 
can be categorized into two classes on the basis of the degree of graphitization of the carbon framework. Materials synthesized from carbons prepared at low carbonization temperatures $\left(<450{ }^{\circ} \mathrm{C}\right)$ and $\mathrm{CA} 1$ display high initial activity but rapidly deactivate over $24 \mathrm{~h}$ TOS. As major products, glucose (selectivity after $1 \mathrm{~h}$ TOS: $\left.\mathrm{S}_{1 \mathrm{~h}}=58-79 \%\right)$, fructose $\left(\mathrm{S}_{1 \mathrm{~h}}=2.9\right.$ $3.9 \%)$, mannose $\left(S_{1 \mathrm{~h}}=1.3-1.9 \%\right)$, levoglucosan $\left(S_{1 \mathrm{~h}}=1.7 \%\right)$ and $\operatorname{HMF}\left(\mathrm{S}_{1 \mathrm{~h}}=1.1-1.8 \%\right)$ were formed at $31.0-44.6 \%$ conversion. Under the chosen reaction conditions, levulinic and

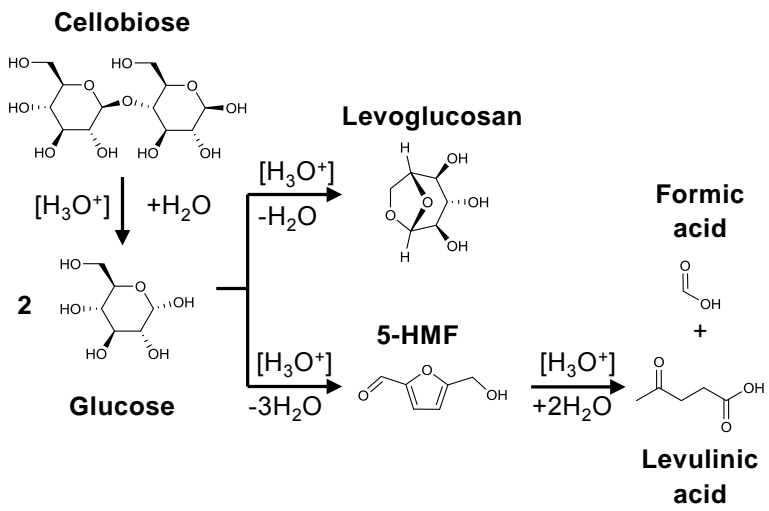

Scheme 1. Reaction pathway for cellobiose in the presence of Brønsted acids.

formic acid were not detected. Since a product was formed in small quantities that could not be directly identified, we employed LC-MS. The fragmentation pattern of this compound points to an isomer of cellobiose (glucose-mannose or glucosefructose). Interestingly, the isomer was the only remaining product after the catalysts had been fully deactivated as well as during the blank experiment. Consequently, its formation is likely related to isomerization reactions of cellobiose induced by exposure to the hydrothermal reaction environment. This is consistent with previous studies that have demonstrated that cellobiose can be isomerized to 4-O- $\beta$-D-glucopyranosyl-Dfructose and 4-O- $\beta$-D-glucopyranosyl-D-mannopyranose in hot compressed water, albeit at higher temperatures than employed in this study. ${ }^{[36]}$ Sulfonated turbostratic carbons carbonized at higher temperature $\left(>450^{\circ} \mathrm{C}\right)$ or HSAG displayed only low activity during hydrolysis reactions. The major product over these materials was the isomer previously identified. Furthermore, smaller amounts of glucose $\left(S_{1 \mathrm{~h}}=8.8-14.9 \%\right)$, fructose $\left(S_{1 \mathrm{~h}}=1.6-2.9 \%\right)$ and mannose $\left(S_{1 \mathrm{~h}}=1.8-2.8 \%\right)$ formed at $10.7-15.3 \%$ conversion. These findings are in line with previous studies, in which materials prepared at lower carbonization temperatures $\left(\leq 450{ }^{\circ} \mathrm{C}^{[33]}{ }^{[37]}\right)$ displayed substantially higher activity during different Brønsted acidcatalyzed reactions performed in batch reactors. It should, however, be noted that control experiments (Figure S7.A) in batch reactors revealed that all materials had undergone extensive sulphur leaching (15-54\% of initial sulphur content). Hence, the activity in batch experiments can be traced back to homogeneous reaction pathways related to leached sulphurcontaining species. This unambiguously shows that batch-based experiments are unsuitable for the catalytic testing of sulfonated carbons. The difference in activity of sulfonated carbons prepared via carbonization at low and high temperatures has

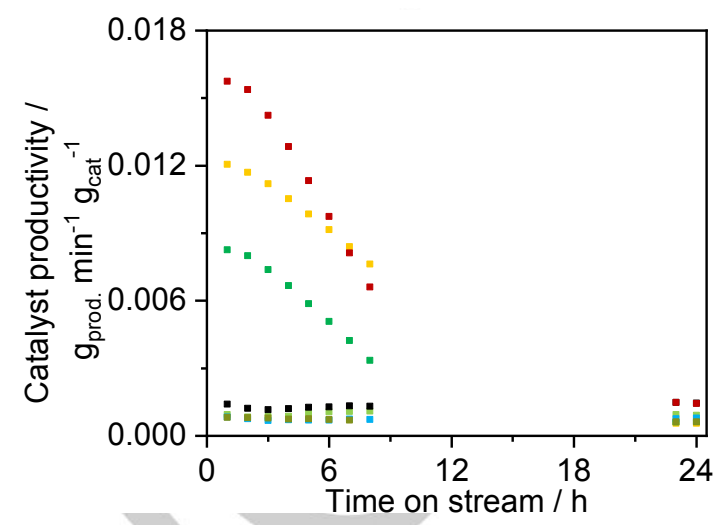

Figure 5. Catalyst productivity of sulfonated carbons during cellobiose conversion. $350-\mathrm{SO}_{3} \mathrm{H}(), 400-\mathrm{SO}_{3} \mathrm{H}(\cdot), 450-\mathrm{SO}_{3} \mathrm{H}(=), 550-\mathrm{SO}_{3} \mathrm{H}(\cdot), 750-$ $\mathrm{SO}_{3} \mathrm{H}("), \mathrm{CA}_{1}-\mathrm{SO}_{3} \mathrm{H}(\cdot)$, and $\mathrm{HSAG}-\mathrm{SO}_{3} \mathrm{H}(=)$. Reaction conditions: $75 \mathrm{mM}$ cellobiose, $130{ }^{\circ} \mathrm{C}$, LHSV $=99 \mathrm{~h}^{-1}, \mathrm{~m}_{\text {cat }}=140-170 \mathrm{mg}$. Reaction conditions HSAG-SO ${ }_{3} \mathrm{H}: 75 \mathrm{mM}$ cellobiose, $130{ }^{\circ} \mathrm{C}$, LHSV $=33 \mathrm{~h}^{-1}, \mathrm{~m}_{\text {cat }}=150 \mathrm{mg}$ (diluted 10:1 with quartz).

previously been attributed to the lacking accessibility of $-\mathrm{SO}_{3} \mathrm{H}$ groups, resulting from increased cross-linking between polyaromatic domains. ${ }^{[26 f]}$ However, these findings can also be interpreted with different sulphur-containing species that are present in the materials prepared at low and high carbonization temperatures. At higher carbonization temperatures, the structure of materials derived from incomplete cellulose carbonization is increasingly characterized by a disturbed graphitic lattice and stacked polyaromatic domains, as evidenced by the rising contribution of the D1 band to the Raman spectra (Figure 3) and the increasing intensity of the (002) reflection (Figure 2). These structural features are a prerequisite for the formation of graphite bisulfate $\left(\left[\mathrm{C}_{24}{ }^{+}\right]\left[\mathrm{HSO}_{4}\right]^{-}\right.$ $2 \mathrm{H}_{2} \mathrm{SO}_{4}$ ) intercalation type compounds, when treating carbons with sulphuric acid and an oxidant. Considering the evolution of structural properties with carbonization temperature, it thus appears possible that the sulphur in samples prepared at higher carbonization temperature or HSAG, is partially present in the form of bisulfate intercalation compounds. The presence of bisulfate intercalation compounds is consistent with the observation that these samples displayed activity in cellobiose hydrolysis during batch-based experiments but not under continuous flow conditions. Because de-intercalation can be induced by exposure to water ${ }^{[38]}$, leached sulphur-containing species can contribute to activity by homogeneous reaction pathways in batch reactors, but not in fixed-bed reactors when they are washed out at high liquid hourly space time velocities. To further substantiate this hypothesis, an additional reference material was synthesized by sulfonation of a well graphitized commercially available multilayer graphene ( $\mathrm{mGra}$ ). The X-ray diffraction pattern of the as delivered mGra sample (Figure S8.B) featured a sharp peak of high intensity, attributed to the 
(002) reflection. As in the case of turbostratic carbons prepared at higher temperatures or materials derived from HSAG, the sulfonated multilayer graphene exhibited activity during batchbased experiments (Figure S7.A) but only very low activity in cellobiose hydrolysis under continuous flow conditions (Figure S8.C). These results further support the hypothesis that sulfonation of well graphitized materials composed of extended and partially crystalline polyaromatic domains, such as turbostratic carbons prepared at higher temperatures, HSAG or the multilayer graphene does not introduce hydrothermally stable sulfonic acid groups. Conversely, sulfonation of such materials leads to the introduction of sulphur-containing species that leach in hydrothermal reaction environments and can participate in homogeneous reaction pathways in batch reaction environments. Sulfonation of materials characterized by a highly amorphous carbon structure such as materials derived from lowtemperature carbonized samples or CA1 introduces sulfonic acid groups that are partially hydrothermally stable and can be clearly identified via FTIR spectroscopy. Sulfonation of these carbons results in highly active catalysts which can retain their Brønsted acidity over several hours' time on stream.

Hydrothermal treatment of sulfonated carbons. Similar to batch-based experiments, all sulfonated materials (Table S1, denoted "carbonization temperature- $\mathrm{SO}_{3} \mathrm{H}-24 \mathrm{~h}$ ") lost a substantial amount of the initially present sulphur (40-68\%) over the course of $24 \mathrm{~h}$ TOS. For the most active sulfonated carbon derived from cellulose carbonization $\left(350-\mathrm{SO}_{3} \mathrm{H}\right), 42 \%$ of its initial sulphur content leached within $4 \mathrm{~h}$ TOS, followed by a more gradual loss (up to $49 \%$ ) within the next $20 \mathrm{~h}$ (Figure S9).

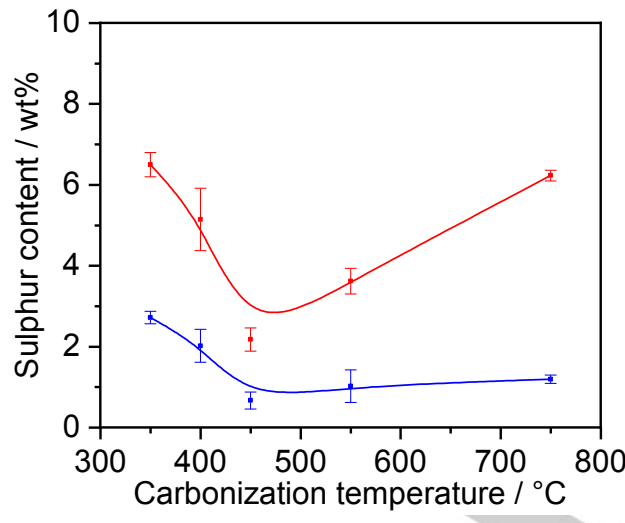

Figure 6. Sulphur content of materials after sulfonation $(-)$ and after hydrothermal treatment (-). Hydrothermal treatment: $180{ }^{\circ} \mathrm{C}, 16.5 \mathrm{~h}, 1 \mathrm{~g}$ sulfonated carbon per $10 \mathrm{~mL}$ Millipore water.

To remove the most hydrothermally labile sulfonic acid groups, the different samples were subjected to hydrothermal treatment at $180{ }^{\circ} \mathrm{C}$ for $16.5 \mathrm{~h}$. Elemental analysis of the different sulfonated carbons derived from cellulose carbonization, before and after hydrothermal treatment, revealed that the stability towards sulphur leaching was strongly dependent on the carbonization temperature employed during synthesis (Figure 6).
Whereas materials carbonized at $<450{ }^{\circ} \mathrm{C}$ contained $2.0-2.7 \%$ sulphur that was stable during the hydrothermal treatment, all materials carbonized at higher temperature contained $0.7-1.2 \%$. Furthermore, the FTIR spectra of the samples $350-\mathrm{SO}_{3} \mathrm{H}-\mathrm{HT}$, $400-\mathrm{SO}_{3} \mathrm{H}-\mathrm{HT}$ and $\mathrm{CA} 1-\mathrm{SO}_{3} \mathrm{H}-\mathrm{HT}$ still show absorption bands at around $1040 \mathrm{~cm}^{-1}$ and $1168 \mathrm{~cm}^{-1}$ (Figure 1), previously attributed to $\mathrm{O}=\mathrm{S}=\mathrm{O}$ stretching modes. These results clearly show that sulfonated carbons derived from low temperature carbonization, or from CA1, contain sulfonic acid groups that are stable towards prolonged exposure to harsh hydrothermal conditions. Consequently the hydrothermal stability of sulfonic acid groups must be related to the structure of the carbonaceous support. Literature suggests that the stability of a sulfonic acid group towards hydrolysis in hydrothermal reaction environments can be correlated with the nature of the carbon moiety that forms the C-S bond. ${ }^{[27]}$ For example, it has been shown that the stability of an alkyl sulfonic acid group is higher than that of an aryl sulfonic acid. ${ }^{[39]}$ The higher stability of the former is related to the fact that the alkyl sulfonic acid cannot undergo acid-catalyzed hydrolysis of the C-S bond. Furthermore, it is known that the electron donating or withdrawing effect of other substituents strongly impacts on the propensity of aromatic systems to undergo sulfonation or desulfonation. ${ }^{[27]}$ Substituents on the benzene ring that reduce the electron density at the $\mathrm{C}-\mathrm{S}$ bond

Table 2. Sulphate yield when subjecting different sulfonic acids to hydrothermal treatment.

\begin{tabular}{|c|c|c|}
\hline $\begin{array}{l}\text { Sulfonic } \\
\text { acid }\end{array}$ & $\begin{array}{l}\text { Sulphate } \\
\text { yield }{ }^{\text {[a] }} \\
130{ }^{\circ} \mathrm{C}\end{array}$ & $\begin{array}{c}\text { Sulphate } \\
\text { yield }{ }^{[a]} \\
180^{\circ} \mathrm{C}\end{array}$ \\
\hline & 0.1 & 0.4 \\
\hline & 3.0 & 36.4 \\
\hline & 3.5 & 4.9 \\
\hline & 0.9 & 0.7 \\
\hline & 0.4 & 1.1 \\
\hline
\end{tabular}

[a] Reaction conditions: $0.2 \mathrm{M}$ sulfonic acid in $\mathrm{H}_{2} \mathrm{O}$ heated to 130 or $180^{\circ} \mathrm{C}$ during $16.5 \mathrm{~h}$.

may entail higher stability towards hydrolysis. It has been hypothesized that this would also influence the stability of sulfonic acid groups in sulfonated carbon catalysts. ${ }^{[26 \mathrm{~d}]}$ To test this hypothesis, different benzene sulfonic acids mimicking the situation with real carbon materials were subjected to hydrothermal treatment and analyzed for their stability (Table 2). Activated aryl sulfonic acids, such as the ortho-hydroxyl or para- 
benzoxy-substituted compounds, were readily desulfonated when exposed to hot compressed water at $130{ }^{\circ} \mathrm{C}$ or $180{ }^{\circ} \mathrm{C}$. Phenols and ethers are activating substituents that increase the electron density in the aromatic system through the mesomeric effect. Consequently the electron density in C-S bonds located in ortho or para position increases, and thus, the desulfonation rate. In contrast, the unsubstituted or the deactivated carboxy-substituted benzene sulfonic acids were not prone to desulfonation even when exposed to temperatures as high as $180^{\circ} \mathrm{C}$. Thus, it can be concluded that the stability of sulfonic acid groups in carbon matrices is associated with the adjacency to electron donating or withdrawing substituents. In turn, the presence or absence of such substituents is determined by the carbonization temperature employed during the synthesis of the turbostratic carbons. Considering the thermal instability of the different oxygencontaining functional groups present in carbon materials, it becomes evident that deactivating substituents (carboxylic acids $200-400{ }^{\circ} \mathrm{C}$, lactones $\left.350-627^{\circ} \mathrm{C}\right)^{[30]}$ would primarily be present in materials prepared by low-temperature carbonization. In contrast, materials prepared at higher carbonization temperature are supposed to contain thermally more stable oxygen-containing surface functionalities such as phenols $\left(600-700{ }^{\circ} \mathrm{C}\right)$ or ethers $\left(700{ }^{\circ} \mathrm{C}\right) .{ }^{[30]}$ The thermal decomposition of oxygen-containing surface functionalities is evidenced by the found oxygen content determined via elemental analysis as well as by the drastic reduction in $\mathrm{IR}$ absorption in the regions associated with $\mathrm{C}=\mathrm{O}$ and $\mathrm{C}-\mathrm{O}$ bonds. Furthermore, the total amount of acidic surface functionalities (sulfonic + carboxylic + phenolic) is drastically reduced for materials carbonized at higher temperatures (Carbonization temperature < $450{ }^{\circ} \mathrm{C}$ : $3497-3727 \mu \mathrm{mol} \mathrm{g}{ }^{-1}$, Carbonization temperature $>450{ }^{\circ} \mathrm{C}$ : $747-1324 \mu \mathrm{mol} \mathrm{g}{ }^{-1}$ ). All these results explain the observation that sulfonation of carbons derived from low-temperature cellulose carbonization $\left(350^{\circ} \mathrm{C}\right.$ and $400{ }^{\circ} \mathrm{C}$ ), or $\mathrm{CA} 1$, results in the formation of a distribution of sulfonic acid sites with varying hydrothermal stability. Furthermore this provides conclusive evidence that the hydrothermal stability is indeed related to the chemical environment of sulfonic acid groups on the carbon support.

Catalytic stability of hydrothermally treated sulfonated carbons: Having demonstrated that the deactivation of sulfonated carbons occurs concerted with sulphur leaching, in a next step the activity and stability of the catalysts after hydrothermal treatment was assessed. As expected, the initial activity of the hydrothermally treated $350-\mathrm{SO}_{3} \mathrm{H}, 400-\mathrm{SO}_{3} \mathrm{H}$ and $\mathrm{CA} 1-\mathrm{SO}_{3} \mathrm{H}$ (Figure 7) samples was reduced due to an overall reduction in the sulfonic acid group density (Table 1). The major products on the hydrothermally treated materials were glucose $\left(S_{1 \mathrm{~h}}=73.1-89.6 \%\right)$, fructose $\left(S_{1 \mathrm{~h}}=2.1-3.3 \%\right)$, mannose $\left(S_{1 \mathrm{~h}}=1.1\right.$ $1.4 \%)$, levoglucosan $\left(\mathrm{S}_{1 \mathrm{~h}}=1.5-1.7 \%\right)$ and 5 - HMF $\left(\mathrm{S}_{1 \mathrm{~h}}=0.6-\right.$ $0.9 \%)$. The corresponding conversion after $1 \mathrm{~h}$ TOS over the different samples was between 34.4 and $75.4 \%$. The samples $350-\mathrm{SO}_{3} \mathrm{H}-\mathrm{HT}$ and $\mathrm{CA} 1-\mathrm{SO}_{3} \mathrm{H}-\mathrm{HT}$ displayed a significantly reduced tendency to continue sulphur leaching (10\% and $17 \%$, respectively, Table S1) during the course of the $24 \mathrm{~h}$ stability test. This can be rationalized by the fact that the hydrothermal pretreatment at $180{ }^{\circ} \mathrm{C}$ leads to the removal of the most labile sulfonic acid groups and that the remaining are predominantly stable under the experimental conditions $\left(130^{\circ} \mathrm{C}\right)$. The sample

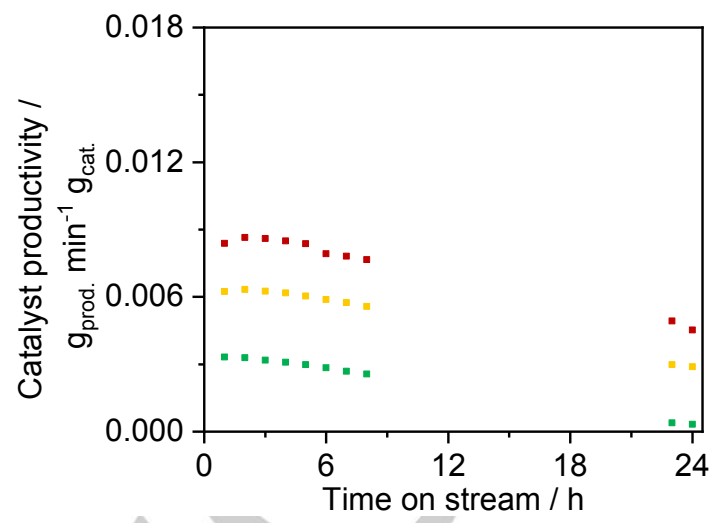

Figure 7. Catalyst productivity of sulfonated carbons for cellobiose conversion after hydrothermal treatment. $350-\mathrm{SO}_{3} \mathrm{H}-\mathrm{HT}\left({ }^{(}\right), 400-\mathrm{SO}_{3} \mathrm{H}-\mathrm{HT}\left({ }^{(}\right)$and $\mathrm{CA} 1-$ $\mathrm{SO}_{3} \mathrm{H}-\mathrm{HT}(\cdot)$. Reaction conditions: $75 \mathrm{mM}$ cellobiose, $130{ }^{\circ} \mathrm{C}$, LHSV $=33 \mathrm{~h}^{-1}$ $\mathrm{m}_{\text {cat }}=520-570 \mathrm{mg}$

$400-\mathrm{SO}_{3} \mathrm{H}-\mathrm{HT}$ also retained substantial activity after hydrothermal treatment, but was still prone to remarkable sulphur leaching (43\%) over $24 \mathrm{~h}$ TOS. After an initial induction period (during the first $2 \mathrm{~h}$ TOS), all materials displayed a constant linear deactivation rate for the remainder of the experiment. The fraction of initial activity lost could, however, not

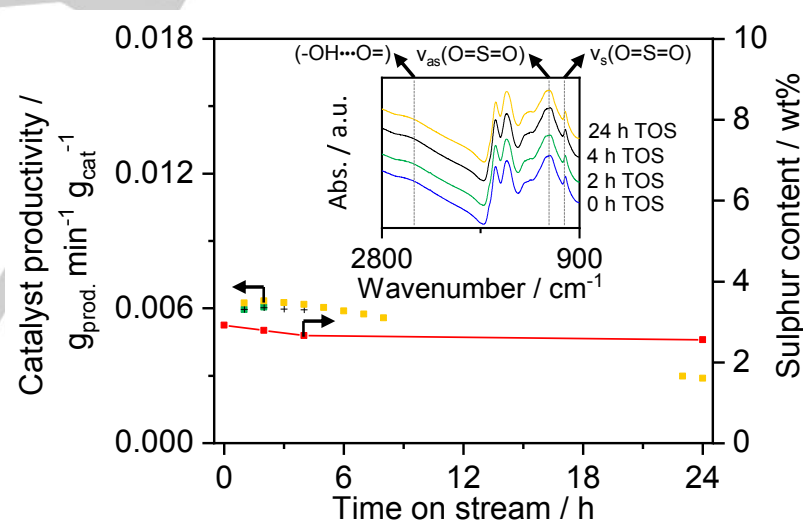

Figure 8. Catalyst productivity, sulphur content and FTIR spectra of 350 $\mathrm{SO}_{3} \mathrm{H}-\mathrm{HT}$ during experiments terminated after $2 \mathrm{~h} \mathrm{(-),} 4 \mathrm{~h} \mathrm{(+)}$ and $24 \mathrm{~h} \mathrm{(")} \mathrm{on}$ stream. Reaction conditions: $75 \mathrm{mM}$ cellobiose, $130{ }^{\circ} \mathrm{C}, \mathrm{LHSV}=33 \mathrm{~h}^{-1}, \mathrm{~m}_{\text {cat }}=$ $495 \mathrm{mg}$.

be explained alone by the continued loss of sulphur during the $24 \mathrm{~h}$ experiment. To investigate the relation between leaching and deactivation rate, three experiments terminated after $2 \mathrm{~h}, 4$ $\mathrm{h}$ and $24 \mathrm{~h} \mathrm{~h}$ TOS, respectively, and using the most active sulfonated and hydrothermally treated turbostratic carbon, were conducted. Figure 8 shows the evolution of catalyst productivity and sulphur content of the sample $350-\mathrm{SO}_{3} \mathrm{H}-\mathrm{HT}$ with TOS. To 
understand if the sulfonic acid groups were subject to chemical transformations that have led to a loss in activity, FTIR spectra of samples collected after $2 \mathrm{~h}, 4 \mathrm{~h}$ and $24 \mathrm{~h}$ TOS were recorded (Figure 8). The IR bands at 1040 and $1168 \mathrm{~cm}^{-1}$ previously assigned to the symmetric and asymmetric stretching modes in $\mathrm{O}=\mathrm{S}=\mathrm{O}$, were well identifiable even after $24 \mathrm{~h}$ TOS. This suggests that $-\mathrm{SO}_{3}$ were still present in protonated or deprotonated form. Additionally, the broad and unresolved feature at $2500 \mathrm{~cm}^{-1}$ previously identified as the $(-\mathrm{OH} \cdots \mathrm{O}=)$ bending mode of Brønsted acids that participate in hydrogen bonding, is also still clearly identifiable even after $24 \mathrm{~h}$ TOS. Consequently, a fraction of the sulfonic acid groups is still present in protonated form, which is consistent with the observation that the catalysts retained a fraction of their initial activity over the $24 \mathrm{~h}$ TOS.

The role of ion exchange processes during catalyst deactivation. To understand the influence of an interconversion of protonated and deprotonated sulfonic acid groups on catalyst deactivation, we performed a regeneration experiment in which the deactivated catalysts were treated with a strong Brønsted acid (Figure 9). Cations contained in the aqueous feed solution may induce deactivation by exchanging with protons (proton leaching) of the sulfonic acid groups. This mode of deactivation

$\left(\mathrm{pKs}=-20^{[41]}\right)$, cation-exchanged sulfonic acid groups were regenerated into their protonic-from through secondary ion exchange. After regeneration, the $0.2 \mathrm{M} \mathrm{CF}_{3} \mathrm{SO}_{3} \mathrm{H}$ solution was flushed from the reactor using Millipore water until the $\mathrm{pH}$ at the outlet of the reactor had reached 7 . Before restarting the reaction by heating the reactor, the system was saturated with the $75 \mathrm{mM}$ cellobiose containing feed solution. Figure 9 shows that the catalyst activity could be restored after the first and second catalytic cycle by application of the developed regeneration protocol. On the one hand, this provides strong evidence that ion exchange processes with metal cations contained in the feed solution have a detrimental effect on catalyst stability. On the other hand, this confirms that treatment of the spent catalysts with strong Brønsted acids restored the catalyst activity through reversible ion exchange processes. $\mathrm{CF}_{3} \mathrm{SO}_{3} \mathrm{H}$ acid was found to be a suitable choice as catalyst regeneration agent because of its lower pKs value and its lacking tendency to sulfonate the carbon support during regeneration cycles (Figure 9) or to participate in redox reactions. The latter is confirmed when looking at the carbon content of the catalyst before and after regeneration cycles; the measured $\mathrm{C}$ wt $\%$ after the $1^{\text {st }}, 2^{\text {nd }}$ and $3^{\text {rd }}$ catalytic cycle was $61.5 \%, 61.1 \%$ and $61.6 \%$, respectively. To clarify the origin of cations during stability experiments, the as-prepared $75 \mathrm{mM}$ cellobiose feed solution was analyzed for its metal content using ion chromatography (IC) and

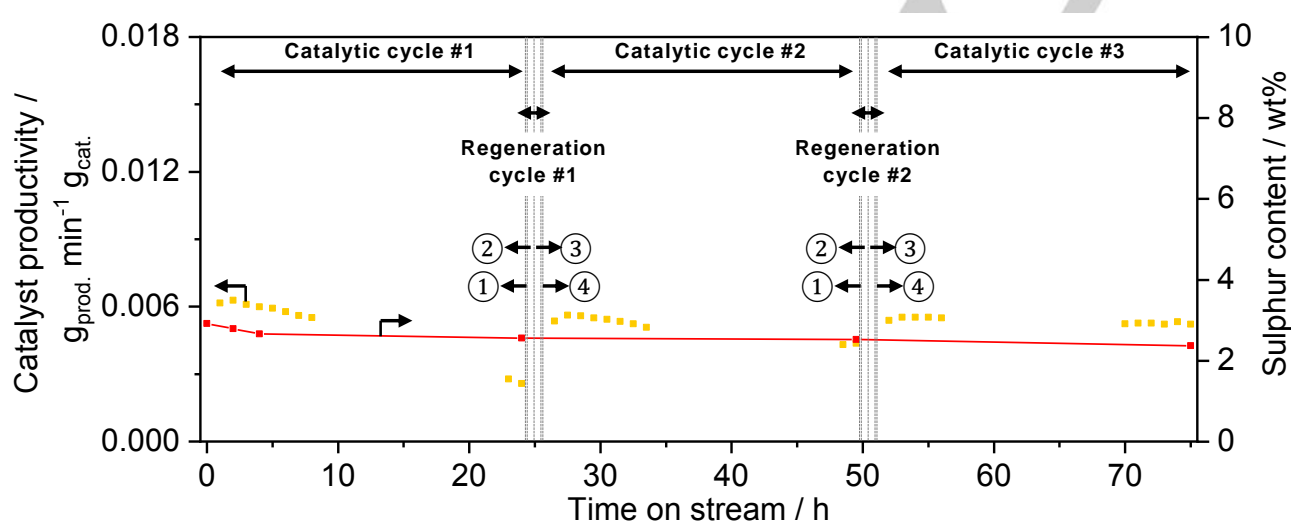
inductively coupled plasma optical emission spectroscopy (ICP-OES). The measured concentrations of $\mathrm{Na}, \mathrm{K}, \mathrm{Mg}$ and Ca were $40 \mu \mathrm{M}, 1.5 \mu \mathrm{M}, 1.3 \mu \mathrm{M}$, and $2.4 \mu \mathrm{M}$, respectively. The concentration of $\mathrm{Cu}$ was determined to be $0.03 \mu \mathrm{M}$. The concentration of $\mathrm{Ni}$ (limit of detection $=5 \mathrm{ppb}$ ) and $\mathrm{Fe}$ (limit of detection $=1 \mathrm{ppb}$ ) where below their respective detection limits. Because the feed solutions

Figure 9. Catalyst productivity of $350-\mathrm{SO}_{3} \mathrm{H}-\mathrm{HT} \quad($ ) during deactivation/regeneration experiments. Catalytic cycle: $75 \mathrm{mM}$ cellobiose, $130{ }^{\circ} \mathrm{C}, \mathrm{LHSV}=33 \mathrm{~h}^{-1}, \mathrm{~m}_{\text {cat }}=495 \mathrm{mg}$. Regeneration cycle: (1) Substrate flushing: $10 \mathrm{~min}$. $2.50 \mathrm{~mL} \mathrm{~min}{ }^{-1}$ Millipore water, $25^{\circ} \mathrm{C}$ (2) Regeneration: $40 \mathrm{~min}$ $1.00 \mathrm{~mL} \mathrm{~min}{ }^{-1} 0.2 \mathrm{M} \mathrm{CF}_{3} \mathrm{SO}_{3} \mathrm{H}, 25^{\circ} \mathrm{C}$ (3) Acid flushing: $40 \mathrm{~min} .2 .50 \mathrm{~mL} \mathrm{~min} \mathrm{~m}^{-1}$ Millipore water, $25{ }^{\circ} \mathrm{C}$ (4) Feed saturation: $5.00 \mathrm{~min}$. $2.50 \mathrm{~mL} \mathrm{~min}^{-1} 75 \mathrm{mM}$ cellobiose.

is commonly regarded to be reversible through a secondary ion exchange of the deactivated sulfonic groups with a stronger Brønsted acid (i.e. pKs (regeneration Brønsted acid) < pKs (immobilized sulfonic acid) $\approx-2.8^{[40]}$ - approximated by the pKs of benzene sulfonic acid). Figure 9 illustrates the evolution of catalyst productivity during three consecutive catalytic cycles (each for $24 \mathrm{~h}$ ), with intermediate regeneration by $\mathrm{CF}_{3} \mathrm{SO}_{3} \mathrm{H}$. At the end of each catalytic cycle, the substrate was flushed from the reactor using Millipore water, followed by catalyst regeneration via treatment with a $0.2 \mathrm{M} \mathrm{CF}_{3} \mathrm{SO}_{3} \mathrm{H}$ solution at room temperature. Due to the higher $\mathrm{pKs}$ value of triflic acid were all prepared with Millipore water, the identified metal impurities are very likely residuals of the cellobiose production process. To further corroborate the role of ion exchange processes on catalyst deactivation, an experiment using an artificial cation-enriched feed solution $\left(0.25 \mathrm{wt} \% \mathrm{Na}^{+}(2.8 \mathrm{mM})\right.$, $\mathrm{K}^{+}(1.7 \mathrm{mM}), \mathrm{Mg}^{2+}(2.7 \mathrm{mM})$ and $\mathrm{Ca}^{2+}(1.6 \mathrm{mM})$ based on weight of cellobiose in the feed solution) was conducted. As expected, in this case the catalysts exhibited significantly accelerated deactivation rates (Figure S10 - Catalytic cycle \# 1) due to the higher rate of ion exchange processes. Treatment of the fully deactivated catalysts with triflic acid could, however, fully restore the materials Brønsted acidity again (Figure S10 - Catalytic cycle \# 2). To the best of our knowledge, this demonstrates for the first time that ion exchange processes with cations contained in the reaction environment have a detrimental but not irreversible effect on catalytic activity. The developed regeneration protocol can fully restore the catalyst activity after deactivation, and thereby enables stable operation of the solid 
Brønsted acid catalysts. In theory, regeneration should also be achievable with any Brønsted acid possessing a pKs value lower than that of the immobilized sulfonic acid.

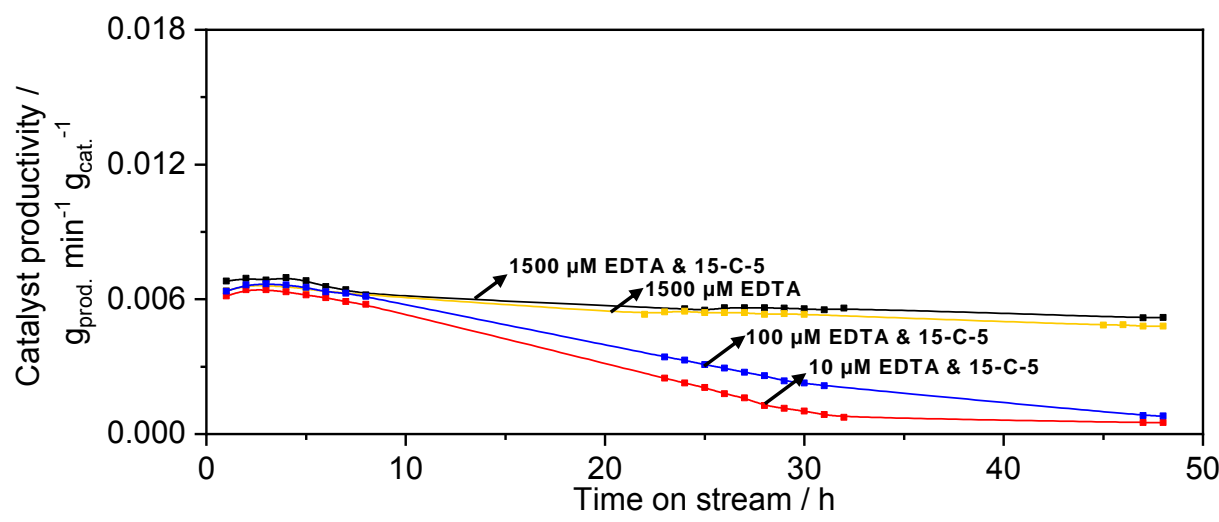

That is to say that, complexation of the very low amounts of monovalent ions with the 15-crown-5 polyether should expectedly lead to only a marginal decrease in deactivation rate. On the other hand, the concentration of EDTA required to stabilize the catalyst is significantly higher than the concentration of divalent cations identified via ICPOES and IC. This suggests that very large stoichiometric excesses of EDTA are required to sufficiently reduce the concentration of free divalent cations to a level where the rate of ion exchange processes is slowed. The addition of complexating agents to the liquid feed presents an interesting alternative to the regeneration procedure using very strong homogeneous Brønsted acids. In combination with the use of hydrothermally pre-treated sulfonated carbon catalysts derived from carbon materials with a low degree of graphitization, the developed strategies enable the stable operation solid-acid catalysts in liquid phase reaction environments. with different concentrations of EDTA and 15-crown-5. $10 \mu \mathrm{M}$ EDTA \& $10 \mu \mathrm{M}$ 15-Crown-5 ("), $100 \mu \mathrm{M}$ EDTA \& $100 \mu \mathrm{M}$ 15-Crown-5 ("), $1500 \mu \mathrm{M}$ EDTA (") and $1500 \mu \mathrm{M}$ EDTA \& $1500 \mu \mathrm{M}$ 15-Crown-5 (•). Reaction conditions: $75 \mathrm{mM}$ cellobiose + complexating agents, $130^{\circ} \mathrm{C}$, LHSV $=33 \mathrm{~h}^{-1}, \mathrm{~m}_{\mathrm{cat}}=495 \mathrm{mg}$.

Because the handling of strong Brønsted acids poses significant challenges to safe handling on a technical scale we investigated alternative means for stabilizing the catalyst against deactivation via ion exchange processes. Suppression of the cations ability to exchange with protons of sulfonic acid groups should theoretically be possible by formation of strong and stable complexes with suitable complexation agents. To form complexes with the identified mono- and divalent cations we added crown ethers and ethylenediaminetetraacetic acid (EDTA) respectively, as complexation agents to the liquid feed. EDTA is known to form very stable chelate complexes with a large spectrum of divalent metal cations and should consequently suppress their ability to ion exchange with protons of the sulfonic acid groups. Similarly crown ethers form very stable complexes with a variety of small cations, including ions of the alkali metals but also first row transition metals. Because of its high affinity for complexation of $\mathrm{Na}^{+}$, we used the 15-crown-5 polyether to chelate the $\mathrm{Na}^{+}$cations identified by ion chromatography. Figure 10 shows the evolution of catalyst productivity using feed solutions enriched with different concentrations of EDTA and 15crown-5. As hypothesized the catalyst stability could be enhanced due to the suppression of ion exchange processes. This effect becomes already evident at concentrations of complexating agents of $100 \mu \mathrm{M}$ EDTA and $100 \mu \mathrm{M}$ 15-crown-5 polyether. A further increase in the complexating agent concentration to $1500 \mu \mathrm{M}$ (EDTA \& 15-crown-5) resulted in a further drastic decrease of the deactivation rate. Interestingly the rate of deactivation during an experiment where only $1500 \mu \mathrm{M}$ EDTA was added to the feed was only marginally higher than when both EDTA and 15-crown-5 were added to the feed. On the one hand, this result is consistent with the very low concentration of monovalent cations detected in the liquid feed.

\section{Conclusions}

Sulfonation of carbons with a low degree of graphitization yielded active solid acid catalysts that feature $-\mathrm{SO}_{3} \mathrm{H}$ groups which are partially hydrothermally stable. A material prepared from cellulose carbonized at $350{ }^{\circ} \mathrm{C}$ displayed the highest sulphur retention capability and catalytic stability. The stability of $-\mathrm{SO}_{3} \mathrm{H}$ groups in carbon materials was demonstrated to be related to their adjacency to activating or deactivating substituents. The deactivation of sulfonated carbons in hydrothermal reaction environments was shown to occur via the concerted effect of sulfonic acid group and proton leaching. Through a hydrothermal pre-treatment the most labile sulfonic acid groups were removed so that the resulting catalyst displayed significantly improved sulphur retention and catalytic stability. Proton leaching was demonstrated to be driven by ion exchange with cationic impurities contained in the feed and was shown to be a fully reversible mode of deactivation by treatment of the spent catalysts with strong Brønsted acids. Furthermore the ability of cations to ion exchange with sulfonic acid groups could be suppressed through addition of suitable metal complexation agents to the aqueous feed. The developed regeneration protocol and stabilization strategy enabled stable operation of sulfonated carbons in hydrothermal reaction environments and consequently has particular significance for application in real biomass conversion processes. The adverse effect of the high mineral content of biomass on catalyst stability could be counterbalanced through application of the developed regeneration-stabilization protocol and thereby enables utilization of solid acid catalysts in lignocellulose conversion processes. Additionally, elucidation of the role of substituent effects in the stability of sulfonic acid groups provides insights 
for the design of stable solid acid catalysts for applications in hydrothermal reaction environments. This includes not only biomass conversion processes but in practice any aqueous phase Brønsted-acid catalyzed reaction for which otherwise non-recoverable homogeneous acids are typically employed.

\section{Experimental Section}

Materials: $\quad \mathrm{D}-(+)-$ Cellobiose $\quad(\mathrm{TCl}, \quad>98 \%), \quad \mathrm{D}-(+)-$ Glucose monohydrate (Sigma-Aldrich, $\geq 99 \%$ ), D-(-)-Fructose (Fluka, $>99 \%$ ), D-(+)-Mannose (Sigma-Aldrich, $\geq 99 \%$ ), D-(+)-Galactose (Sigma-Aldrich, $\geq 99 \%$ ), Furfural (Sigma-Aldrich, 99\%), 5hydroxymethyl)furfural (Sigma-Aldrich, 99\%), 1,6-Anhydro- $\beta$-DGlucose (Sigma-Aldrich, 99\%), Levulinic acid (Sigma-Aldrich, $99 \%$ ) and Formic acid (Sigma-Aldrich, $\geq 98 \%$ ) were used as external calibration standards. Analytics: Quantification of substrate and reaction products was achieved using an Agilent 1260 Infinity HPLC system, equipped with a refractive index detector operated at $35^{\circ} \mathrm{C}$, and an Aminex Biorad carbohydrate column (HPX-87 C, $300 \times 7.8 \mathrm{~mm}$ ). The column was operated at $80{ }^{\circ} \mathrm{C}$ and at a flowrate of $0.45 \mathrm{~mL} \mathrm{~min}^{-1}$ using Millipore water as the eluent. Conversion (X) of cellobiose (CB) and the selectivity $(\mathrm{S})$ in formation of product $(I)$ was calculated using the following equations: $\mathrm{X}=1-\left(\mathrm{C}_{\mathrm{CB}} / \mathrm{C}_{\mathrm{CB}, 0}\right) \quad(I)$ and $\mathrm{S}=\left(\mathrm{C}_{j} / \mathrm{C}_{\mathrm{CB}, 0}\right) / \mathrm{X}(I I) . \mathrm{C}_{\mathrm{CB}, 0}$ denotes the initial concentration of cellobiose, $C_{C B}$ the concentration of cellobiose at a given point in time and $c_{i}$ the concentration of product $i$ at a given point in time. Measurement of the $\mathrm{m} / \mathrm{z}$ ratios of unknown compounds was performed on a Thermo Scientific Ultimate 3000 equipped with $Q$ Exactive Focus mass spectrometer and the Aminex (HPX-87C) carbohydrate analysis column.

Synthesis of carbons: Turbostratic carbons were prepared according to Suganuma et al. ${ }^{[26 \mathrm{c}]}$ Briefly, cellulose (15 g, SigmaAldrich, Avicel PH-101, $50 \mu \mathrm{m}$ ) was carbonized under constant argon flow $\left(250 \mathrm{~mL} \mathrm{~min}{ }^{-1}\right)$, in a Carbolite CTF (12/65) tubular oven equipped with a quartz tube. The oven was heated to the desired temperature $\left(350-750{ }^{\circ} \mathrm{C}\right)$ at a constant rate of $10{ }^{\circ} \mathrm{C}$ $\mathrm{min}^{-1}$, and held at the set-point for $5 \mathrm{~h}$. Subsequently the oven was allowed to cool to room temperature at a constant cooling rate of $10^{\circ} \mathrm{C} \mathrm{min}^{-1}$. The temperature inside the quartz tube was monitored with a thermocouple installed directly under the quartz crucible. Sulfonation of carbons: Sulfonation was achieved through heating the carbons derived from incomplete carbonization in oleum $\left(15 \mathrm{~mL} 20 \% \mathrm{SO}_{3} / \mathrm{H}_{2} \mathrm{SO}_{4}\right.$ per $1 \mathrm{~g}$ of carbon) to $80{ }^{\circ} \mathrm{C}$ for $16.5 \mathrm{~h}$ under constant $\mathrm{N}_{2}$ flow $\left(5 \mathrm{~mL} \mathrm{~min}{ }^{-1}\right.$ ). Reference materials were synthesized from activated carbon (Sigma-Aldrich, Norit-CA1), high surface area graphite (TIMCAL, TIMREX RC-053) and multilayer graphene nanoplatelets (TCl, 2-10 $\mathrm{nm}$ thick and $5 \mu \mathrm{m}$ wide). After sulfonation, catalysts were recovered through filtration, washed with $1 \mathrm{~L}$ of deionized water at room temperature and $2 \mathrm{~L}$ of deionized hot water $\left(90-95^{\circ} \mathrm{C}\right)$, and finally dried at $110{ }^{\circ} \mathrm{C}$ overnight. Hydrothermal treatment of sulfonated carbons: Hydrothermal treatment of sulfonated carbons was performed in Ace pressure tubes (front-seal, 15 $\mathrm{mL}$ ) through suspending carbon samples $(1 \mathrm{~g})$ in Millipore (10 $\mathrm{mL}$ ), and heating to $180{ }^{\circ} \mathrm{C}$ during $16.5 \mathrm{~h}$ under autogenous pressure. After hydrothermal treatment catalysts were recovered, washed and dried in the same manner as the sulfonated samples.

Batch cellobiose hydrolysis: Batch hydrolysis of cellobiose $(75 \mathrm{mM})$ dissolved in Millipore water $(10 \mathrm{~mL})$ was performed in Ace pressure tubes using a catalyst to substrate mass ratio of 1:5. The cellobiose containing solution and catalyst were thoroughly mixed before immersing the Ace pressure tube for 2 $\mathrm{h}$ into a silicon oil bath preheated to $130^{\circ} \mathrm{C}$. The reaction was quenched through immersing the Ace pressure tubes in cold water. Hydrolysis of cellobiose under continuous flow conditions: Hydrolysis of cellobiose $(75 \mathrm{mM})$ dissolved in Millipore water was performed in a tailor-made continuous liquidphase reactor setup consisting of a fixed-bed reactor (length $=3$ or $9 \mathrm{~cm}, 6 / 4 \mathrm{~mm}$ o.D./i.D Swagelok stainless steel tubing) connected at the inlet, via $1 / 16$ inch Swagelok tubing, to an HPLC pump (Knauer P4.1S) and at the outlet to a back-pressure valve (Tescom, $26-1700$ series) that maintained a backpressure of 20 bar in the system. The fixed-bed reactor was equipped with a pre-heat column (length $=3 \mathrm{~cm}, 6 / 4 \mathrm{~mm}$ o.D./i.D Swagelok stainless steel tubing) filled with $2 \mathrm{~mm}$ borosilicate glass beads. After pressurizing the system, the reactor was immersed in a silicon oil bath preheated to the desired temperature using a stirring hot plate. Liquid samples were collected every hour for 4 minutes at the outlet of the backpressure valve. Residence times in the fixed-bed reactor were calculated by assuming an inter-particle void fraction of 0.40 . After every continuous flow experiment the reactor was removed from the oil bath and allowed to cool to room temperature during $1 \mathrm{~h}$, while pumping Millipore water at $1.00 \mathrm{~mL} \mathrm{~min}^{-1}$ through the reactor. Regeneration of catalyst activity was achieved through treatment of the catalysts with $0.2 \mathrm{M}$ trifluoromethanesulfonic acid (Sigma-Aldrich, 98\%). Accelerated deactivation by an artificial cation-enriched feed solution was achieved through dissolution of chloride salts of $\mathrm{Na}, \mathrm{K}, \mathrm{Mg}$ and $\mathrm{Ca}$ in Millipore water. The tendency of cations to ion exchange with protons of the sulfonic acid groups was suppressed by addition of ethylenediaminetetraacetic acid (Fluka, >99\%) and 15-crown-5 (SigmaAldrich, 98\%) to the aqueous cellobiose containing feed. Hydrothermal treatment of model compounds: Hydrothermal treatment of benzene sulfonic acid (Sigma-Aldrich, 98\%), 2phenolsulfonic acid (Sigma-Aldrich, 99\%), dibenzofuran sulfonic acid (Alfa Aesar, 97\%), 2-sulfobenzoic acid hydrate (Alfa Aesar, 98\%), 3-sulfobenzoic acid monosodium salt (Alfa Aesar, 97\%), performed in Ace pressure tubes by dissolving sulfonic acids $(0.20 \mathrm{M})$ in Millipore water $(10 \mathrm{~mL})$, and heating to $130{ }^{\circ} \mathrm{C}$ or $180^{\circ} \mathrm{C}$ during $16.5 \mathrm{~h}$.

Elemental analysis: Carbon, sulphur and nitrogen weight percent were measured on an Elementar Vario EL Cube device. The combined oxygen and hydrogen weight percent where determined by difference to $100 \%$. The nitrogen content was below $0.1 \mathrm{wt} \%$ in all samples. Ion chromatography: Quantification of cation and anion concentration was performed on a Metrohm 850 Professional IC device equipped with Metrosep A SUPP (150/4 mm) and a Metrosep C4 (150/4 mm) column for separation of anions and cations and a conductivity detector. The Metrosep C4 column was operated isocratically 
using $2.8 \mathrm{mM} \mathrm{HNO}_{3}$ solution as eluent. The Metrosep A was operated with a step-gradient using $0.75 \mathrm{mM}(8 \mathrm{mM}) \mathrm{Na}_{2} \mathrm{CO}_{3}$ and $0.15 \mathrm{mM}(1.7 \mathrm{mM}) \mathrm{NaHCO}_{3}$ as eluent. Inductively coupled plasma optical emission spectroscopy (ICP-OES): Quantification of transition metals was performed on an Agilent VISTA AX. Powder X-ray diffraction: Powder X-ray diffractograms of carbon samples were measured on a D8 ADVANCE (Bruker) diffractometer using $\mathrm{Cu}$ Ka radiation $(40 \mathrm{kV}$, $40 \mathrm{~mA}$ ) over the range $5-70^{\circ}(2 \theta)$. Gas-physisorption: $\mathrm{N}_{2}$ was used as adsorbate for quantification of the specific surface area in the samples derived from CA1, HSAG and mGra. $\mathrm{N}_{2}$ physisorption was performed on a Quantachrome Instrument (Autosorb I). Due to the very low amounts of adsorbed gas in samples prepared from an incomplete carbonization of cellulose, $\mathrm{Kr}$ physisorption was performed to enable an accurate quantification of the specific surface area. $\mathrm{Kr}$ adsorption was performed on a Micromeritics Tristar II 3020 analyzer. Before the measurement, all samples were degassed at $145{ }^{\circ} \mathrm{C}$ for $24 \mathrm{~h}$. Data point selection for Brunauer-Emmett-Teller (BET) surface area calculation was performed in accordance with the procedure proposed by Rouquerol. ${ }^{[42]}$ Scanning electron microscopy (SEM) and energy dispersive $X$-ray spectroscopy (EDX): Surface morphology and particle size of samples were analyzed using a Zeiss Ultra 55 Field Emission Gun Scanning Electron Microscope. Images were taken using an acceleration voltage of $14 \mathrm{kV}$ at $\times 100, \times 200$ and x2600 magnification. To minimize charging effects, all samples were sputter-coated with a 80:20 Au:Pd alloy using a Leica EM SCD 500 before analysis. Fourier transformed infrared (FTIR) spectroscopy: FTIR spectra of the different samples were measured by preparing pellets of $0.1-0.3 \mathrm{wt} \%$ carbon in $\mathrm{KBr}$. Prior to preparation of the pellets, both the carbon samples and $\mathrm{KBr}$ were dried at $110^{\circ} \mathrm{C}$ overnight. Spectra were recorded on a Bruker Vertex $70 \mathrm{~V}$ FTIR spectrometer in the range 400-4000 $\mathrm{cm}^{-1}$ using a resolution of $2 \mathrm{~cm}^{-1}$. Raman spectroscopy: Raman spectra were recorded on Labram HR800 Horiba-Jobin Yvon confocal Raman instrument using the red light of a $632.8 \mathrm{~nm} \mathrm{He}-$ $\mathrm{Ne}$ Laser. Reported spectra are the average of two scans. Peak fitting was performed with the OPUS Spectroscopy software (Bruker) in accordance with the procedure proposed by Sadezky. ${ }^{[43]}$ Peak fitting was conducted on rubberband baselinecorrected and normalized spectra (to the intensity of the $G$ band) using a Levenberg Marquardt minimization algorithm. The algorithm optimized the peak position, width and height of a combination of 4 Lorentzian (D1, D2, D4 and G) and 1 Gaussian (D3) peaks to achieve an optimal fit to the experimental data. Quantitative analysis of surface functionalities via Boehm Titration: Quantitative measurement of the total amount of surface functionalities was accomplished by Boehm titration. 0.5 $\mathrm{g}$ of sulfonated-, or hydrothermally treated-, carbons were suspended in $50 \mathrm{~mL} 0.05 \mathrm{M} \mathrm{NaOH}$ and stirred for $24 \mathrm{~h}$ at room temperature. After filtering the carbon and degassing the filtrate during $2 \mathrm{~h}$, a $10 \mathrm{~mL}$ aliquot was acidified with $20 \mathrm{~mL} 0.05 \mathrm{M} \mathrm{HCl}$ and backtitrated with $0.05 \mathrm{M} \mathrm{NaOH}$. Each titration was performed twice.

\section{Acknowledgements}

This research project is financially supported by the Swiss Innovation Agency Innosuisse and is part of the Swiss Competence Center for Energy Research SCCER BIOSWEET. The authors would like to thank Erich De Boni for help with recording SEM images, Sabina Brütsch for performing ion chromatography measurements, Silvia Köchli for performing ICP-OES measurements and Eibar Joel Flores Cedeño for help with performing Raman measurements.

Keywords: Carbon • Acidity • Deactivation • Hydrothermal • Biomass

[1] A. Koutinas, C. Du, R. Wang, C. Webb, in Introduction to Chemicals from Biomass (Eds.: J. Clark, F. Deswarte), John Wiley \& Sons Ltd., Weinheim, 2008, pp. 77-101.

[2] H. Chen, in Biotechnology of Lignocellulose - Theory and Practice, Springer, Dordrecht, 2014, pp. 25-71.

[3] H. Jørgensen, J. Kristensen, C. Felby, Biofuels, Bioprod. Bioref. 2007, $1,119-134$.

[4] a) M. Sasaki, Z. Fang, Y. Fukushima, T. Adschiri, K. Arai, Ind. Eng. Chem. Res. 2000, 39, 2883-2890; b) M. Sasaki, B. Kabyemela, R. Malaluan, S. Hirose, N. Takeda, T. Adschiri, K. Arai, J. Supercrit. Fluids 1998, 13, 261-268.

[5] J. Luterbacher, D. Alonso, J. Dumesic, Green Chem. 2014, 16, 48164838.

[6] A. Peterson, F. Vogel, R. Lachance, M. Fröling, M. Antal, Energy Environ. Sci. 2008, 1, 32-65.

[7] a) W. Faith, Ind. Eng. Chem. 1945, 37, 9-11; b) D. Thompson, H. Grethlein, Ind. Eng. Chem. Prod. Res. Dev. 1979, 18, 166-169; c) J. Harris, A. Baker, A. Conner, T. Jeffries, J. Minor, R. Pettersen, R. Scott, E. Springer, T. Wegner, J. Zerbe, Gen. Tech. Rep. FPL 1985, 45.

[8] F. Bergius, Ind. Eng. Chem. 1937, 29, 247-253.

[9] S. M. Selke, M. C. Hawley, Ind. Eng. Chem. Prod. Res. Dev. 1982, 21, $11-16$.

[10] L. Vilcocq, P. Castilho, F. Carvalheiro, L. Duarte, ChemSusChem 2014 7, 1010-1019.

[11] R. Rinaldi, F. Schüth, ChemSusChem 2009, 2, 1096-1107.

[12] A. Onda, T. Ochi, K. Yanagisawa, Green Chem. 2008, 10, 1033-1037.

[13] a) R. Rinaldi, R. Palkovits, F. Schüth, Angew. Chem. 2008, 120, 8167-8170; Angew. Chem. Int. Ed. 2008, 47, 8047-8050; b) J. Hegner, K. Pereira, B. DeBoef, B. Lucht, Tetrahedron Lett. 2010, 51, 2356-2358.

[14] M. Marzo, A. Gervasini, P. Carniti, Carbohydr. Res. 2012, 347, 23-31.

[15] S. Van-de-Vyver, L. Peng, J. Geboers, H. Schepers, F. deClippel, C. Gommes, B. Goderis, P. Jacobs, B. Sels, Green Chem. 2010, 12, 1560-1563.

[16] a) R. Ravenelle, F. Schüler, A. D'Amico, N. Danilina, J. van-Bokhoven, J. Lercher, C. Jones, C. Sievers, J. Phys. Chem. C 2010, 114, 1958219595; b) R. Ravenelle, J. Copeland, W. Kim, J. Crittenden, C. Sievers ACS Catal. 2011, 1, 552-561; c) R. Pollock, G. Gor, B. Walsh, J. Fry, I. Ghampson, Y. Melnichenko, H. Kaiser, W. DeSisto, M. Wheeler, B. Frederick, J. Phys. Chem. C 2012, 116, 22802-22814.

[17] a) H. Xiong, M. Nolan, B. Shanks, A. Datye, Appl. Catal., A 2014, 471, 165-174; b) H. Pham, A. Anderson, R. Johnson, T. Schwartz, B. O'Neill, P. Duan, K. Schmidt-Rohr, J. Dumesic, A. Datye, ACS Catal. 2015, 5 , 4546-4555.

[18] a) A. Shrotri, H. Kobayashi, A. Fukuoka, ChemSusChem 2016, 9 , 1299-1303; b) A. Shrotri, H. Kobayashi, A. Fukuoka, ChemCatChem 2016, 8, 1059-1064.

[19] J. Anderson, R. Johnson, K. Schmidt-Rohr, B. Shanks, Carbon 2014 $74,333-345$.

[20] M.Hara, T. Yoshida, A. Takagaki, T. Takata, J. Kondo, S. Hayashi, K. Domen, Angew. Chem. 2004, 116, 3015-3018; Angew. Chem. Int. Ed. 2004, 43, 2955-2958.

[21] a) A. Pelt, O. Simakova, S. Schimming, J. Ewbank, G. Foo, E. Pidko, E. Hensen, C. Sievers, Carbon 2014, 77, 143-154; b) G. Foo, A. Pelt, D. Krötschel, B. Sauk, A. Rogers, C. Jolly, M. Yung, C. Sievers, ACS Sustainable Chem. Eng. 2015, 3, 1934-1942; c) A. Onda, T. Ochi, K. Yanagisawa, Top. Catal. 2009, 52, 801-807.

[22] R. Liu, X. Wang, X. Zhao, P. Feng, Carbon 2008, 46, 1664-1669.

[23] P. Gupta, S. Paul, Green Chem. 2011, 13, 2365

[24] B. Oliveira, V. d. Silva, Catal. Today 2014, 234, 257-263.

[25] F. Liu, W. Kong, L. Wang, X. Yi, I. Noshadi, A. Zheng, C. Qi, Green Chem. 2015, 17, 480. 
[26] a) M.Toda, A. Takagaki, M. Okamura, J. Kondo, S. Hayashi, K. Domen, M. Hara, Nat. Commun. 2005, 438, 178; b) A. Takagaki, M. Toda, M. Okamura, J. Kondo, S. Hayashi, K. Domen, M. Hara, Catal. Today 2006, 116, 157-161; c) S. Suganuma, K. Nakajima, M. Kitano, D. Yamaguchi, H. Kato, S. Hayashi, M. Hara, JACS 2008, 130, 12787 12793; d) M. Kitano, D. Yamaguchi, S. Suganuma, K. Nakajima, H. Kato, S. Hayashi, M. Hara, Langmuir 2009, 9, 5068-5075; e) X. Mo, D López, K. Suwannakarn, Y. Liu, E. Lotero, J. Goodwin, C. Lu, J. Catal. 2008, 254, 332-338; f) K. Fukuhara, K. Nakajima, M. Kitano, H. Kato, S. Hayashi, M. Hara, ChemSusChem 2011, 4, 778-784; gK. Nakajima, M. Okamura, J. N. Kondo, K. Domen, T. Tatsumi, S. Hayashi, M. Hara, Chem. Mat. 2009, 21, 186-193.

[27] O. Lindner, L. Rodefeld, in Benzenesulfonic Acids and their Derivatives, Ullmann's Encyclopedia of Industrial Chemistry Wiley-VCH, Weinheim, 2012, pp. 269-305

[28] J. M. Fraile, E. García-Bordejé, E. Pires, L. Roldán, Journal of Catalysis 2015, 324, 107-118.

[29] P. Chung, A.Charmot, O. Olatunji-Ojo, K. Durkin, A. Katz, ACS Catal. 2014, 4, 302-310.

[30] J. Figueiredo, M. Pereira, M. Freitas, J. Orfao, Carbon 1999, 37, 13791389.

[31] Y. Wang, Z. lqbal, S. Mitra, JACS 2006, 128, 95-99.

[32] R. Buzzoni, S. Bordiga, G. Ricchiardi, G. Spoto, A. Zecchina, J. Phys. Chem. 1995, 99, 11937-11951.

[33] K. Nakajima, M. Hara, ACS Catal. 2012, 2, 1296-1304.

[34] A. Sadezky, H. Muckenhuber, H. Grothe, R. Niessner, U. Pöschl, Carbon 2005, 43, 1731-1742.

[35] a) O. Beyssac, B. Goffe, J.-P. Petitet, E. Froigneux, M. Moreau, J.-N Rouzaud, Spectrochim. Acta A 2003, 59, 2267-2276; b) M. Knauer, M. Schuster, D. Su, R. Schlögl, R. Niessner, N. Ivleva, J. Phys. Chem. A 2009, 113, 13871-13880.

[36] a) Z. Shafie, Y. Yu, H. Wu, Ind. Eng. Chem. Res. 2014, 53, 1460714616; b) Y. Yu, Z. M. Shafie, H. Wu, Ind. Eng. Chem. Res. 2013, 52 17006-17014.

[37] M. Okamura, A. Takagaki, M. Toda, J. Kondo, K. Domen, T. Tatsumi, M. Hara, S. Hayashi, Chem. Mat. 2006, 18, 3039-3045.

[38] W. C. Oh, N. K. Bae, Y. J. Choi, Y. S. Ko, Carbon 1995, 33, 323-327.

[39] J. Anderson, R. Johnson, K. Schmidt-Rohr, B. Shanks, Catal. Commun. 2014, 51, 33-36.

[40] J. P. Guthrie, Can. J. Chem. 1978, 56, 2342-2354.

[41] S. Hien (Siemens AG), EP 0955562 A1, 1999.

[42] J. Rouquerol, P. Llewellyn, F. Rouquerol, Stud. Surf. Sci. Catal. 2007, 160, 49-63.

[43] A. Sadezky, H. Muckenhuber, H. Grothe, R. Niessner, U. Pöschl, Carbon 2005, 43, 1731-1742.

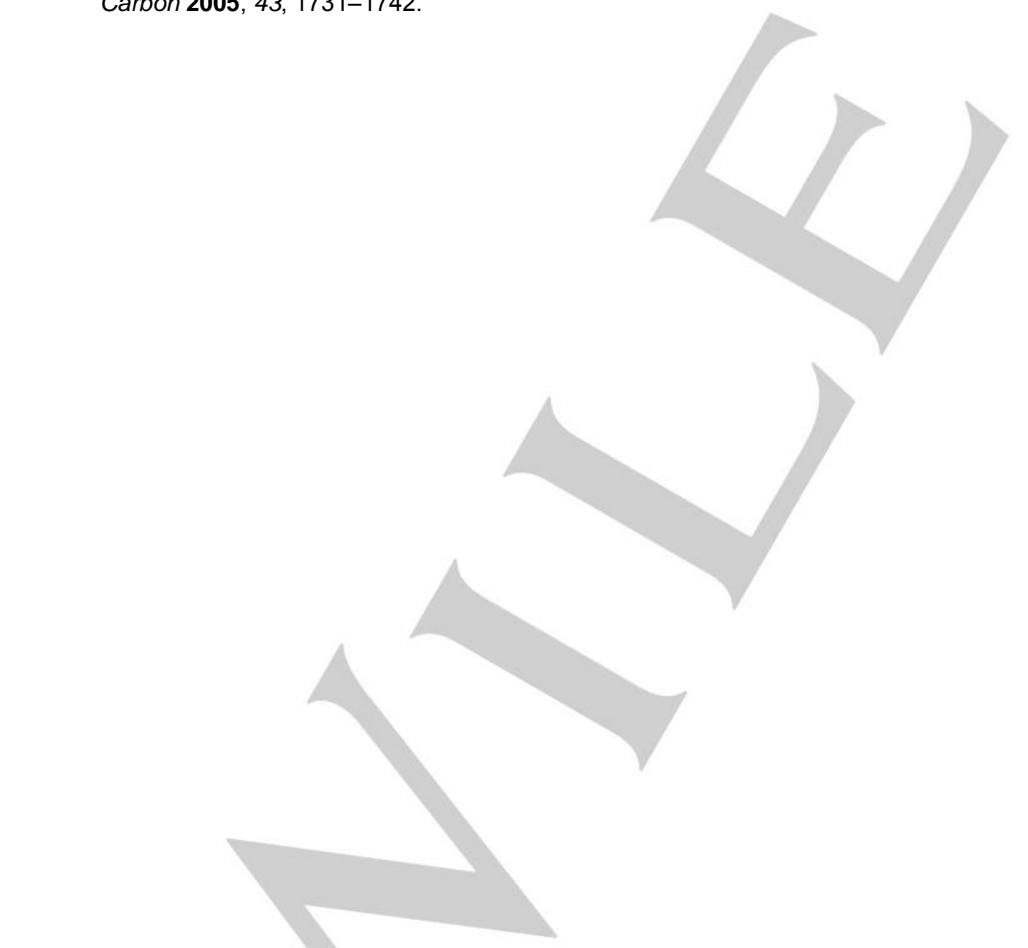




\section{Entry for the Table of Contents}

Layout 1:

\section{FULL PAPER}

The deactivation of sulfonated carbon catalysts in hydrothermal reaction environments is shown to occur via the concerted effect of sulfonic acid group and proton leaching. Stability of sulfonic acid groups is demonstrated to be defined by the structure of the carbonaceous support. Proton leaching is a fully reversible mode of deactivation by treatment of spent materials with stronger Brønsted acids.

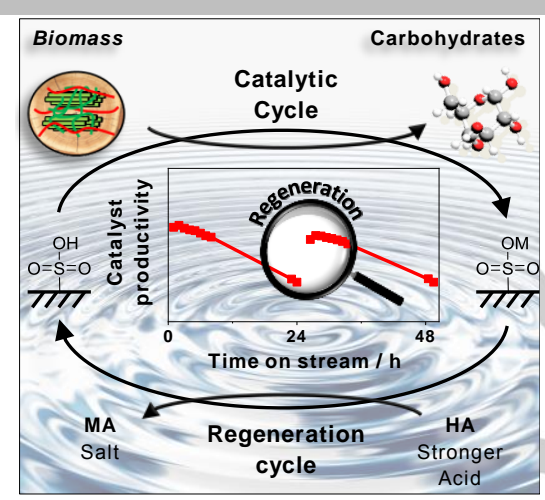

David Scholz, Prof. Oliver Kröcher, Prof. Frédéric Vogel*

\section{Page No. - Page No.}

Deactivation and Regeneration of Sulfonated Carbon Catalysts in Hydrothermal Reaction Environments 